\title{
Mind Your Purpose: Intervening on Mindfulness to Promote Daily Levels of Purpose
}

\author{
By
}

Robin K. Young

A thesis submitted to the Faculty of Graduate and Postdoctoral Affairs in partial fulfillment of the requirements for the degree of

Master of Arts

In

Psychology

Carleton University

Ottawa, Ontario

(C) 2014, Robin K. Young 


\title{
MINDFULNESS INTERVENTION ON DAILY PURPOSE
}

\author{
Abstract \\ In three studies, mindfulness was assessed as a candidate for promoting purpose in life \\ through its effect on moods, stress and daily activities. Studies 1 and 2 provided evidence \\ that purpose and mindfulness were strongly related but independent predictors of well- \\ being using cross-sectional, online samples. Furthermore, the relationship between \\ mindfulness and purpose was partially explained through moods and stress. In Study 3, a \\ brief online mindfulness intervention versus positive affirmation control group design \\ was implemented in 65 college and university students. Results of Study 3 demonstrated \\ that daily purpose fluctuates as a function of mindfulness, daily moods, activities and \\ stress. Across the three studies, mindfulness was positively related to purpose cross- \\ sectionally and it influenced daily purpose above and beyond the effects of moods and \\ stress. This series of studies provides an important contribution to the understanding of \\ purpose in life and mindfulness and has broader implications for positive psychology \\ interventions.
}


Table of Contents

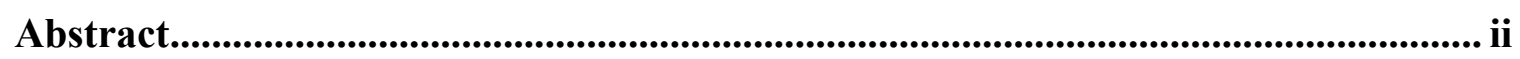

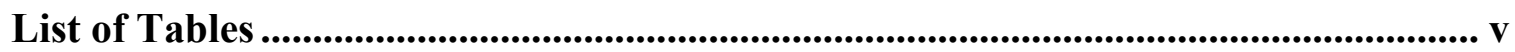

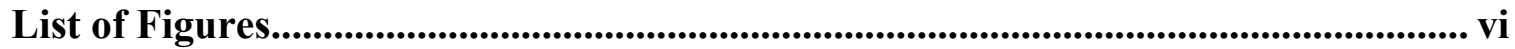

List of Appendices........................................................................................... vii

Chapter 1: Defining Mindfulness ................................................................................ 1

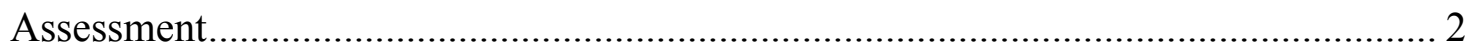

Facets predicting psychological constructs ...................................................... 5

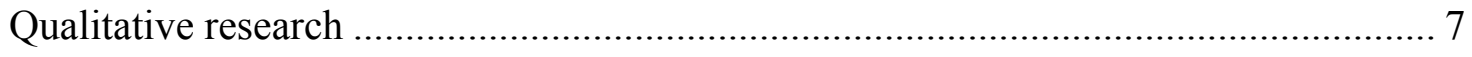

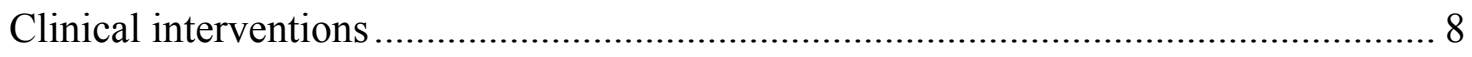

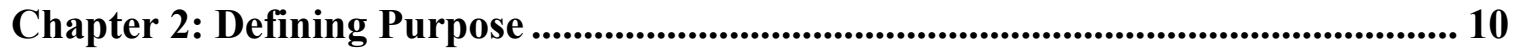

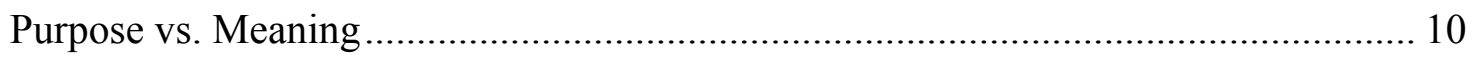

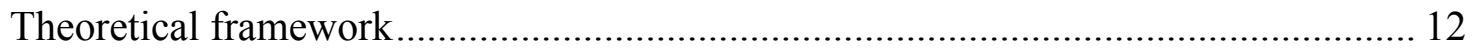

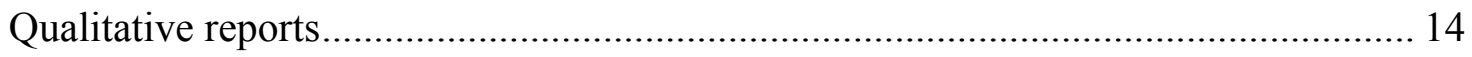

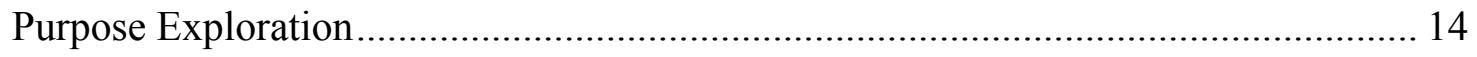

Chapter 3: Comparisons between purpose and mindfulness ...................................... 15

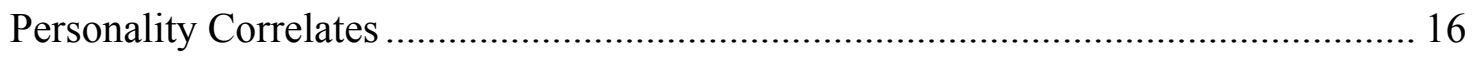

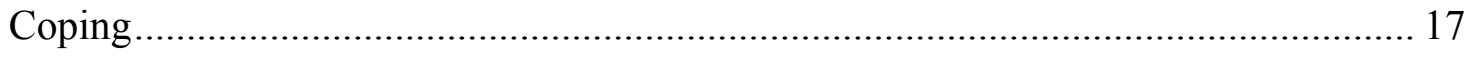

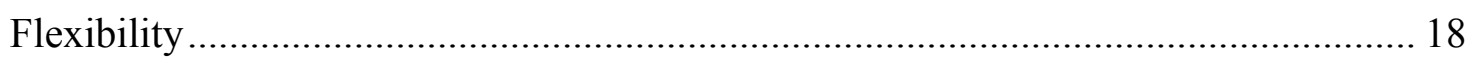

Psychological and Affective Well-being ............................................................. 19

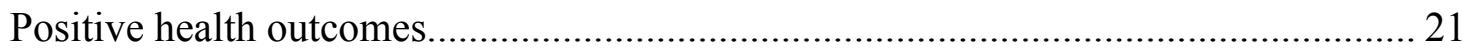

Chapter 4: Why Might Mindfulness Influence Purpose .......................................... 22

Pathway 1 - Increased Positive Affect ............................................................... 23 


\section{MINDFULNESS INTERVENTION ON DAILY PURPOSE}

Pathway 2 - Reduced Negative Affect and Stress .................................................. 23

Pathway 3 - Daily Activities ................................................................................. 25

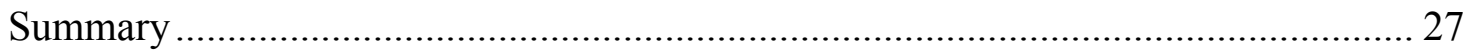

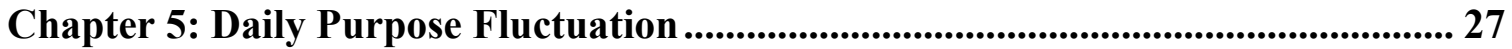

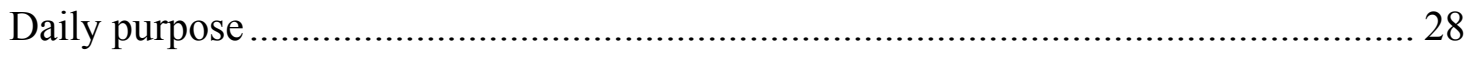

Chapter 6: Current Studies .............................................................................................. 30

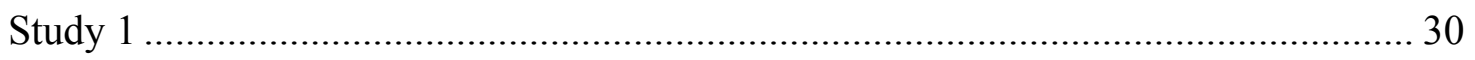

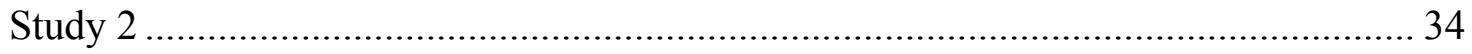

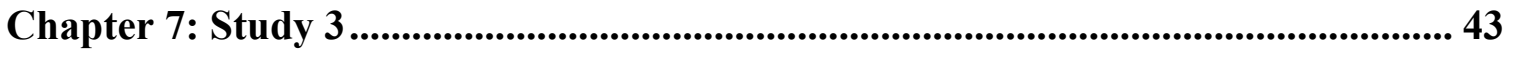

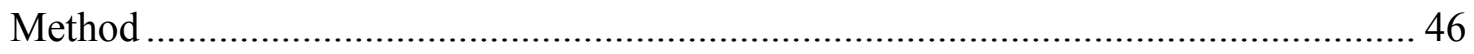

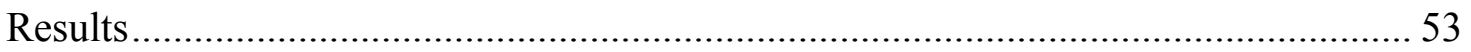

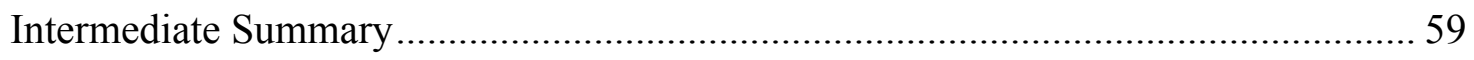

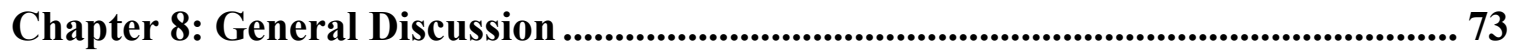

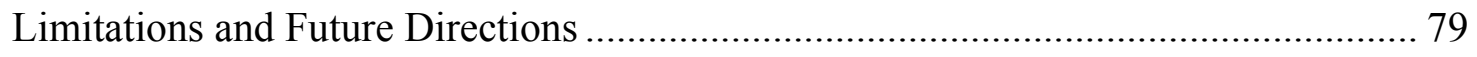

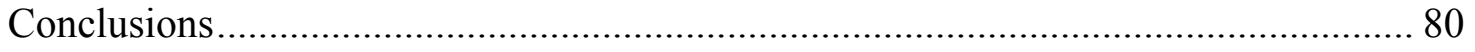

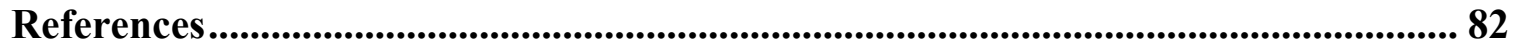

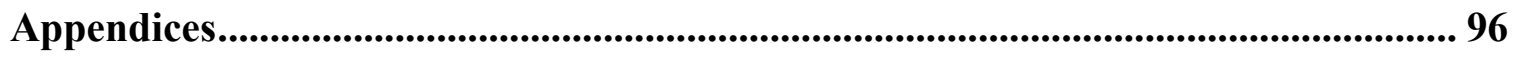




\section{MINDFULNESS INTERVENTION ON DAILY PURPOSE}

\section{List of Tables}

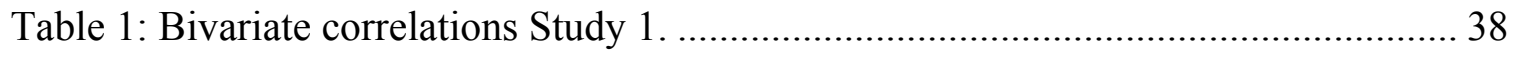

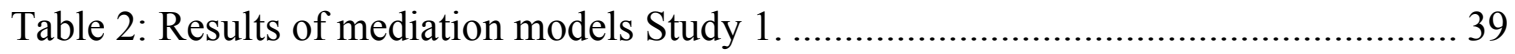

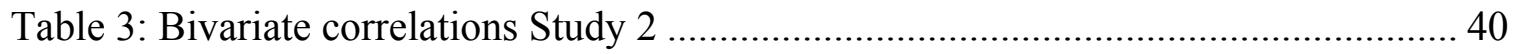

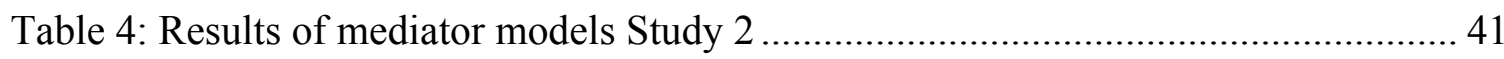

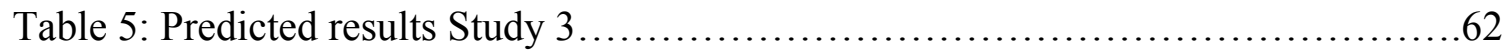

Table 6: Bivariate correlations pre-and post-test in mindfulness condition..............63

Table 7: Bivariate correlations pre-and post-test in control condition .................64

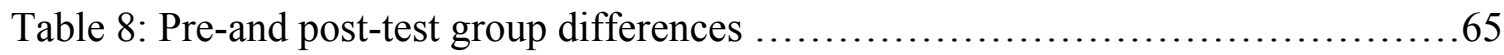

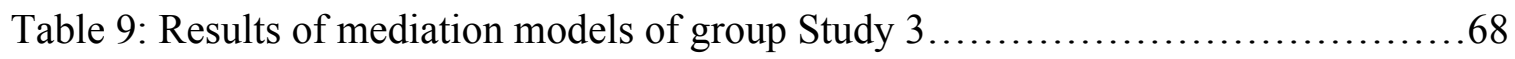

Table 10: Results of mediation models of trait mindfulness Study $3 \ldots \ldots \ldots \ldots \ldots \ldots . \ldots 6$

Table 11: Model estimates for predicting daily purpose from positive affect............70

Table 12: Model estimates for predicting daily purpose from negative affect............71

Table 13: Model estimates for predicting daily purpose from daily activities............72 
MINDFULNESS INTERVENTION ON DAILY PURPOSE

\section{List of Figures}

Figure 1. Three proposed pathways between mindfulness and purpose........................ 22

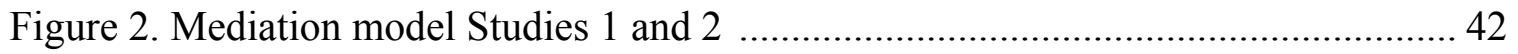

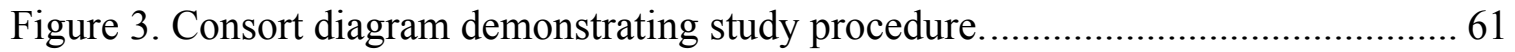

Figure 4. Mediation model for Study 3 group predicting purpose $\ldots \ldots \ldots \ldots \ldots \ldots \ldots \ldots 6$

Figure 5. Mediation model for Study 3 trait mindfulness predicting purpose ...........67 
MINDFULNESS INTERVENTION ON DAILY PURPOSE

vii

\section{List of Appendices}

\section{Pre-test measures}

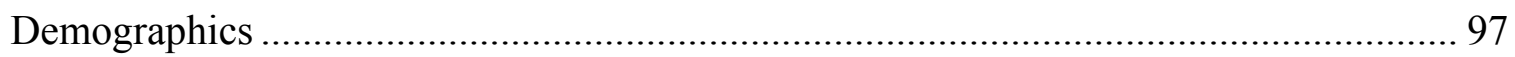

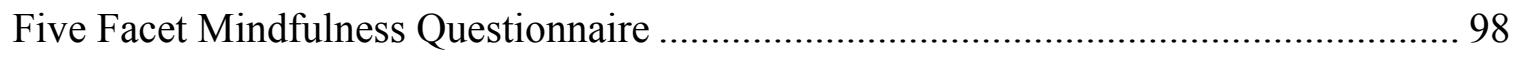

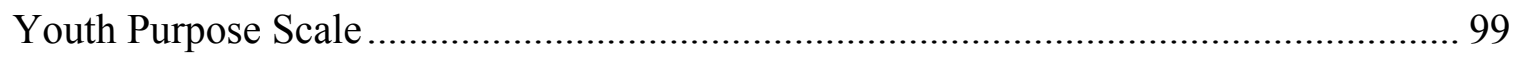

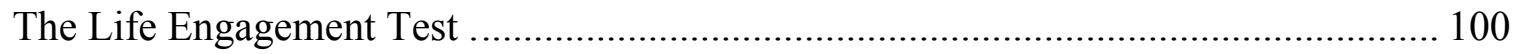

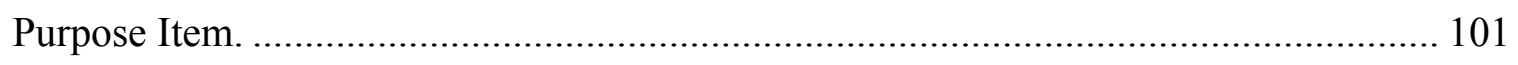

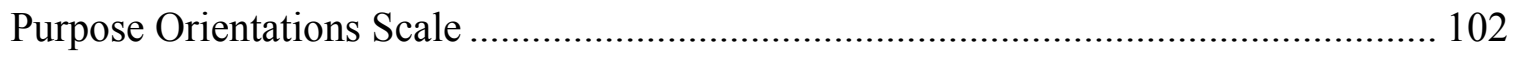

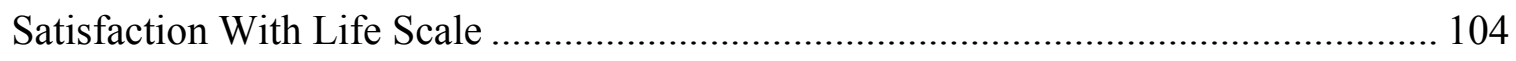

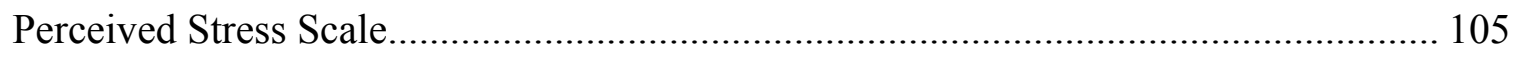

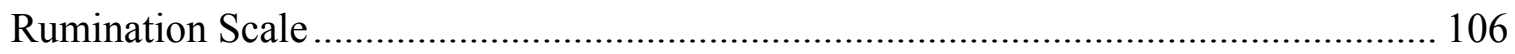

Daily Measures

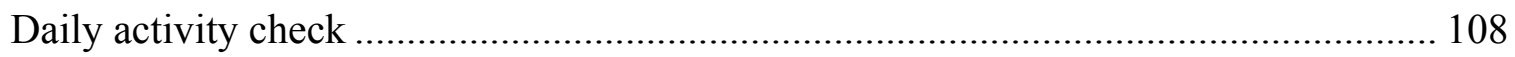

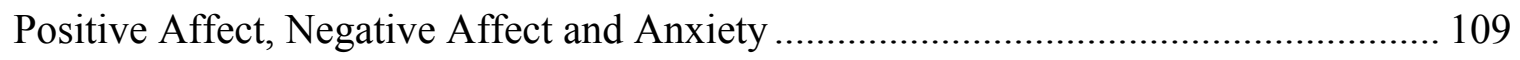

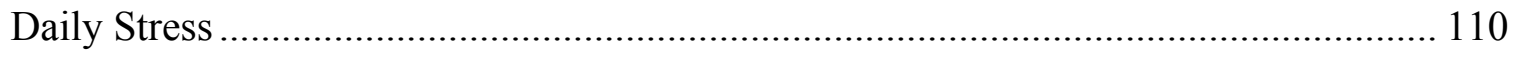

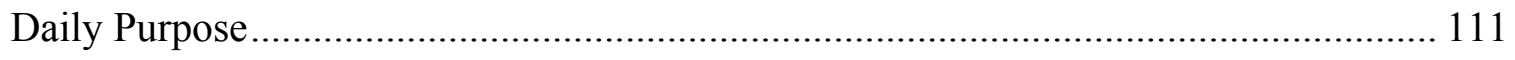

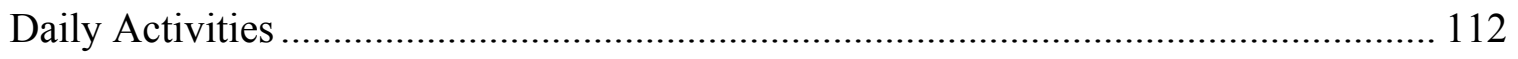

\section{Treatment Protocol}

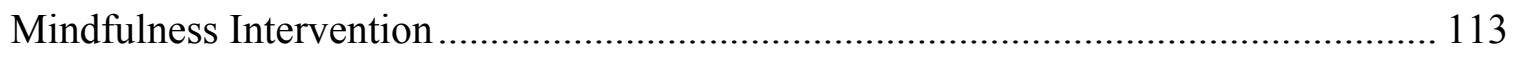

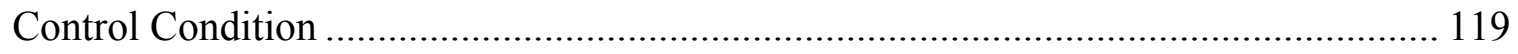


Mind Your Purpose: Intervening on Mindfulness to Promote Daily Levels of Purpose

\section{Chapter 1: Defining Mindfulness}

Mindfulness is rooted in Buddhist and other contemplative traditions, but only recently have researchers sought to operationalize mindfulness and have had moderate success. Research on mindfulness has grown over the past three decades, with mindfulness-based interventions showing promise as treatment for various psychological and psychosomatic illnesses (Kabat-Zinn, 2003). Mindfulness is considered a metacognitive skill that involves monitoring and directing one's attention to the present moment when the mind wanders (Giluk, 2009). Across definitions of dispositional everyday mindfulness, most emphasize a state of conscious attention and awareness, coupled with an open, accepting orientation to experience (Bishop et al., 2004). This section will elaborate on this definition of mindfulness by outlining current scales used to assess the construct. To that extent, qualitative reports of mindfulness will be explored to validate the current multifaceted approach.

Given its somewhat ethereal nature in religious teachings, it is perhaps unsurprising that there is disagreement in the literature regarding how to best conceptualize and define the scope of mindfulness (Bergogi, 2013). Mindfulness has been operationalized as a trait (Brown \& Ryan, 2003), an induced state of consciousness (Bishop et al., 2004) and a multidimensional construct (Baer, Smith \& Allen, 2004). Across articles, researchers often use the same definition of mindfulness and arrive at similar conclusions regarding implications of mindfulness, despite the vastly different measures used to operationalize the construct. To aid understanding of the differences in 
how mindfulness is conceptualized, it is valuable to expand on how mindfulness is defined by most common scales.

\section{Assessment}

When assessing mindfulness as a disposition, the scales used to measure mindfulness suggest a single dimension (Mindful Attention Awareness Scale, Brown \& Ryan, 2003), two-dimensional conceptualizations (Philadelphia Mindfulness Scale, Cardaciotto et al., 2008), to even four to five different dimensions (Kentucky Inventory Mindfulness Scale, Baer et al., 2004; Five Facet Mindfulness Questionnaire, Baer et al., 2008). Starting from a single dimension of mindfulness as simply present moment attention, working up to multi-faceted models, additional factors refine the construct by including attitudes related to meditation training. Across scales, each self-report measure minimally includes an assessment of awareness, underscoring its central role in defining mindfulness.

Single-factor model. Acting with awareness is a central component to mindfulness, and is often used synonymously with the word mindfulness. The Mindful Attention Awareness Scale assesses mindfulness as one's ability to have open, focused observation of internal and external stimuli (MAAS, Brown \& Ryan, 2003). Despite being the most frequently used scale of mindfulness, it fails to capture the nonjudgmental and accepting attitudinal component of mindfulness. If distressful feelings and thoughts are ruminated on, rather than observed and accepted, attending to negative internal stimuli can be maladaptive. While there is evidence that mindfulness interventions reduce emotional reactivity to stressors, single-factor assessments focused on awareness, fail to assess this component of responding to thoughts and feelings 
(Brown, Ryan \& Creswell, 2007). Whereas awareness of the present moment is a foundational component to mindfulness, many researchers have argued that the single factor model fails to capture the complexity and predictive utility that adopting a particular attitude plays in outcomes assessed after mindfulness training (Brown, Ryan \& Creswell, 2007.)

Two-factor model. A two-factor conceptualization of mindfulness includes selfregulation of attention to the present moment and adopting an attitude of curiosity, openness, and acceptance of experience (Bishop et al., 2004). The self-regulation component includes both observation of one's internal experience, as well as acting with awareness (Bergogi, et al., 2013). Inclusion of the attitudinal components of acceptance and openness is an important advancement from the single-factor conception of mindfulness as it starts to distinguish between simple attention and concentration and includes the attitudinal components associated with the mindfulness training programs. However further refinement is required to address other aspects of a mindful person not captured by simple awareness.

Multi-faceted models. To address the disparate definitions and measures of everyday mindfulness, Baer and colleagues (2006) conducted a factor analysis of multiple existing measures (Baer, Smith, Hopkins, Krietemeyer, \& Toney, 2006). The results suggested five distinct factors of mindfulness, which were subsequently combined to create the Five Factor Mindfulness Questionnaire (FFMQ; Baer, et al, 2006). The fivefactor definition of mindfulness entails (1) acting with awareness, the adoption of a (2) non-judgmental and (3) non-reactive attitude, and the ability to (4) observe and (5) describe one's internal and external environment. The five facets generally fit together 
(correlations between factors ranging from .32 to .56) with each facet independently accounting for variance in the overall construct (Baer, Smith, Lykins, Button, Krietemeyer, Sauer, Walsh, Duggan \& Williams, 2008; Cash \& Whittingham, 2010). Several of these factors were included in past definitions, but this was the first time that all five are presented as central, distinct components.

1) Consistent with previous definitions, acting with awareness entails attentiveness to one's present experiences and actions. When acting with awareness, the present moment experience of stimuli is enhanced, allowing for a response that reflects the current situation rather than habitual responses, thereby increasing the capacity to respond to stimuli flexibly (Brown \& Ryan, 2003). People low on this trait would lack self-awareness and would likely respond to stressors in reactive and habitual patterns rather than in a thoughtful and deliberate manner.

2) Non-judgment of inner experience describes a person's ability to have a noncritical or non-evaluative reaction to their thoughts, sensations, and feelings. A nonjudgmental attitude is characterized by welcoming and accepting sensations and experiences (Kabat-Zinn, 1994). Individuals scoring low in this facet are likely to be distressed by negative experiences or blame themselves for negative thoughts or emotions. The attitude of non-judgment allows the individual to experience stress without engaging in self-blame or brooding (Ciesla, Reilly, Dickson, Emanuel \& Updegraff, 2012).

3) Non-reacting entails one's ability to take life as it comes, to experience thoughts and feelings but also let them pass without responding in habitual patterns of reactivity. The quality of non-reactivity is thought to be a way of operationalizing an 
attitude of acceptance (Baer et al., 2006). People low on this trait are likely to be particularly sensitive to distressing external or internal experiences. Individuals high in this trait would have greater capacity to accept occurrence of stressors, not to dwell on them.

4) The facet of observe concerns the degree to which an individual attends to his or her present experiences. An individual low in this facet may demonstrate a lack of awareness not only of the environment but also of his or her own thought processes and emotional states. Close attention or observation to internal stimuli can be maladaptive or adaptive based on how the individual responds to the negative thoughts and feelings (Baer et al., 2004). If negative thoughts and sensations are considered in a nonjudgmental and accepting way, emotional reactivity may be reduced. However, if the negative thoughts are ruminated on, emotional reactivity may be exacerbated. For this reason, the facet of observe may be sensitive to changes with meditation experience that alters in relation to the other variables regarding the attitude adopted when observing one's inner experience.

5) Individuals high on the describe trait are better able to articulate and describe their thoughts, emotions and feelings in words (Ciesla et al., 2012). Individuals low on this facet may be aware of positive and negative experiences but lack the ability to recognize emotions or articulate their thoughts.

\section{Facets predicting psychological constructs}

Utilizing a more refined approach to studying mindfulness helps to describe the potential influence of mindfulness on aspects of psychological well-being, and maladjustment (Hofmann, Sawyer, Witt \& Oh, 2010). For instance, in an article 
comparing the five facets of mindfulness in relation to depression, anxiety, and stress, the pattern of findings demonstrate the potential for facets to act differently when predicting well-being (Cash \& Whittingham, 2010). The facet of non-judgment was the strongest predictor of psychological symptoms (depression, anxiety, and stress), neuroticism, thought suppression, emotion regulation, and experiential avoidance. As the second strongest predictor, higher levels of acting with awareness were related to significantly lower levels of depressive symptoms. Non-reactivity was also significantly related to indicators of dysphoric affect. In a non-meditating sample, each facet except for observe, independently predicted psychological well-being (Baer et al, 2008). The observe facet only predicted psychological well-being among participants that have a regular meditation practice. Thus, the utility of studying mindfulness as five facets is underscored by work demonstrating that these factors differentially predict maladaptive outcomes.

In summary, the five-factor solution is preferable for three primary reasons. First, it is derived from and incorporates the other current mindfulness measures. Second, it captures both the lay Western understanding of mindfulness as present awareness, and the Buddhist attitudes of mindfulness that are encouraged in mindfulness meditation programs. Third, separation of the facets allows for a more clear approach when assessing which components of mindfulness are driving the effects on well-being. Investigating facets of mindfulness is likely to improve our understanding of specific skills cultivated by practicing mindfulness and how these skills are differentially related to psychological adjustment.

For the current series of studies, mindfulness is considered a multi-faceted disposition characterized by the ability to describe, observe and actively engage with the 
present moment, with an accepting and open attitude. As further support for this operationalization, qualitative studies of mindfulness will be considered below that confirm that the experience of mindfulness is described as more than just awareness.

\section{Qualitative research}

Utilizing qualitative reports with quantitative data enriches evaluation by ensuring that the proposed factors derived from factor analysis and quantitative methods are aligned with experience and theoretical conceptualizations of mindfulness. Indeed, the themes described by participants appear consistent with the multi-dimensional mindfulness theory. Participants describe mindfulness as being able to stay present in the moment, and being accepting and non-judgmental of uncomfortable situations (Mackenzie, Carleson, Munoz, and Speca, 2007). Cancer survivors who completed a Mindfulness-Based Stress Reduction (MBSR) program stated that learning mindfulness skills allowed an inner orientation to experience which enabled a recognition of habitual thought patterns and the ability to choose an appropriate response to stress rather than just reacting (Mackenzie et. al., 2007). These themes map onto the facets of observing and acting with awareness, non-reactivity to experience and being able to describe one's thoughts.

An additional qualitative assessment of MBSR participants echoed the themes above with descriptions of mindfulness as a tool to both maintain a consistent state of mind, and to bring attention to the present moment (Morone, Lynch, Losasso, Liebe \& Grecco, 2012). Participants described experiencing a sense of freedom from constant worrying or thinking, and increased self-awareness. They described being able to notice the current environment and their emotions before reacting negatively to the experience. 
These descriptions provide valuable insight to how people experience and understand the concept of mindfulness. Both people's descriptions of mindfulness, and empirical findings converge on the conclusion that mindfulness is a multi-faced construct. The way people experience and articulate mindfulness is more than simply acting with awareness. Empirical assessments from clinical interventions of mindfulness provide further evidence towards this claim, as participants show increases in all dimensions of mindfulness rather than just acting with awareness (Carmody, Baer, Lykins, \& Olendzki, 2009).

\section{Clinical interventions}

Interventions such as MBSR (Kabat-Zinn, 1990) and Mindfulness-Based Cognitive Therapy (MBCT; Seagle et al., 2002) have been developed based on Buddhist traditions to increase mindfulness skills as well as influence a number of psychosocial and physical health outcomes including reducing depression, anxiety, and chronic pain (Grossman et al., 2008). Mindfulness-based interventions draw traditions from the Buddhist insight meditation technique called Vipassana meditation used to see things with bare awareness and develop awareness of body sensations (Goleman, 1988; Hart, 1987). Mindfulness meditation is a formal technique that cultivates mindfulness skills such as attention and awareness so the skills can be transferred to other contexts (Shapiro, Carlson, Astin \& Freedman, 2006).

A benefit of the 8-week MBSR program is the ability to take techniques learned in class, and practice them at home and in daily life (Shapiro et al., 2006). Due to the overwhelmingly positive evidence for the efficacy of the MBSR program, alternate curriculums have been developed that adapt elements for different populations, such as 
decreasing the length of the program, the number of in-class hours, or even the elimination of in-class hours entirely. Recently, interventions as brief as 2 weeks have been compared to the typical 8-week intervention programs and shown comparable effect sizes (Carmody \& Baer, 2009). In that meta-analysis of mindfulness interventions for the reduction of psychological distress, effect sizes did not differ based on the number of hours spent in mindfulness class for both clinical and non-clinical samples. Indeed, several brief online meditation interventions ranging from two to six weeks have provided empirical support for the effectiveness of these programs to reduce perceived stress, anxiety, and increasing mindfulness, positive affect and coping efficacy, whereas the wait-list control showed no change in outcomes (Cavanagh, et al., 2013; Davis \& Zautra, 2013; Glück \& Maecker, 2011). Although these studies have concentrated on formal meditation techniques to improve mindfulness, some have utilized informal mindful engagement in daily activities such as walking or yoga (Krusche, Chylorova, King \& Williams, 2012). In the six-week online mindfulness based program, participants were asked to practice one formal and one informal mindful practice each day; however, data was only reported for formal meditation practice, so it was not possible to determine the independent effects informal activities (Krusche et al., 2012). Little research has been devoted to understanding the active elements of why mindfulness programs promote beneficial outcomes. The formal practice of meditation is related to the focus of attention and development of awareness, whereas informal practice may be related to increasing the attitudes associated with mindfulness such as acceptance and non-judgment.

\section{Summary}


There is a strong and growing body of evidence that supports the efficacy of mindfulness-based clinical programs for increasing mindfulness. Further, these increases in mindfulness reflect changes on a number of well-being indices. To determine why mindfulness influences everything from daily affect, to coping mechanisms, and even life satisfaction, it is necessary to adopt a definition that allows for fine-grained analysis of the construct. A multi-faceted definition of mindfulness provides a more comprehensive approach to understand which components influence the large variety of outcomes. Additionally, it may be important to assess mindfulness outside of clinical settings, utilizing informal practices to gain insight to what exactly it is about mindfulness that is related to emotion regulation, and psychological well-being concepts such as purpose in life.

\section{Chapter 2: Defining Purpose}

The following section seeks to provide an overview of purpose in life. First, purpose in life will be differentiated from the construct of meaning in life, a close conceptual correlate, in order to help better exemplify its unique potential to influence daily life. Second, a theoretical review of five elements of purpose will be outlined. Third, the proposed definition will be compared to how lay people actually view the construct. Fourth, the conceptual distinctions between purpose exploration and a sense of purpose will be addressed.

\section{Purpose vs. Meaning}

Identifying and progressing towards a particular life aim can not only help guide actions and motivate meaningful pursuits, but it may also help provide satisfaction with life (Bronk, Hill, Talib, Finch, \& Lapsley, 2009). Purpose has proven difficult to 
operationalize for two reasons. First, it has roots in in many non-empirically based fields, notably religion and existential philosophy, so it is not surprising that researchers have had difficulty agreeing upon a definition (see Hill, Burrow, \& Sumner, 2013, for a discussion). Second, in both theory and practice, it has proven difficult to distinguish purpose from meaning.

Stemming from life-span developmental theories, Ryff considered purpose as a component of overall well-being, that provides a sense of meaning in one's life (1989b). Ryff describes a person high in purpose as someone that functions with a sense of directedness, has objectives for living, and beliefs that give life meaning. Distinct from this perspective of purpose as a component of meaning, other researchers note that the sense of goal-orientation in purpose plays a separate role in predicating psychological outcomes beyond that of meaning finding (Baumeister, 1991). Whereas meaning involves seeking an explanation or order to life events, purpose entails pursuit of an overarching aim or goal that directs behavior (Damon, Menon \& Bronk, 2003). Pursuit of a purpose provides meaning and direction to one's life, regardless of if the overall aim is actualized. One's purpose is both meaningful to the self and helps dictate which experiences are personally relevant (Baumeister, 1991).

Measuring purpose and meaning has been difficult due to their multi-faceted and subjective nature. An early attempt to operationalize the construct of purpose in life assessed the degree that people reported having found meaning and purpose in life (Crumbaugh \& Maholick, 1967). Building from this, Reker and Peacock (1981) developed a measure for assessment of meaning and purpose that estimated the strength of motivation to find meaning (the Life Attitude Profile, LAP). This scale has subscales 
for purpose and meaning, but the assessment of each construct essentially used the words interchangeably. For instance, meaning was discussed in the measurement of purpose ("The meaning of life is evident in the world around us"), and purpose was used in the assessment of finding meaning ("I am seeking a meaning, purpose, or mission for my life", Reker \& Peacock, 1981). Purpose was broadly defined as an intention or goal to be achieved, whereas meaning was the degree to which someone was able to make sense or bring order to one's life and feel satisfaction (Reker, Peacock \& Wong, 1987, Reker \& Wong, 1988).

In a recent empirical article designed to assess the differential predictors of purpose and meaning, George and Park (2013) defined meaning as a sense of coherence and significance in life, whereas purpose was defined as having a sense of goals, aims and life direction. In this understanding, meaning is more related to interpreting reality and purpose is related to planning and acting on goals. Their findings supported these definitions as constructs that provide a sense of understanding of one's existence, such as religion and spirituality, were uniquely related to meaning when controlling for a sense of purpose. On the other hand, when controlling for meaning, purpose remained related to optimism, and negatively related to perceived stress and pessimism. Purpose as defined by a sense of direction and enthusiasm for the future makes sense that it is related to one's outlook about the future (optimism/pessimism).

\section{Theoretical framework}

A recent review article defined purpose as "a central self-organizing aim, that organizes and stimulates goals, manages behaviors, and provides a sense of meaning" (McKnight \& Kashdan, 2009, p. 242). Purpose provides a basis for development of 
specific shorter term aims to achieve on a daily basis (McKnight \& Kashdan, 2009). The review article further enumerated five theoretical elements of purpose from the previous literature that may be involved in the process by which purpose is central to well-being. First, purpose motivates individuals to engage in behaviours that allow one to circumnavigate obstacles. In support, empirical research has demonstrated purpose as a contributing factor to resiliency and the ability to handle stressors (Ryff, Singer \& Love, 2004). Second, purpose catalyzes approach behaviours, bringing oneself towards achieving goals. Third, purpose is related to greater psychological flexibility when faced with obstacles. A purposeful person is able to see alternatives and manage the environment. Fourth, purpose allows effective responding and dividing resources in an efficient way. Finally, an element of purpose is the ability to process complex higherlevel cognitive processes beyond the motivations for safety and affiliation.

Purpose can be conceptualized on a three-dimensional plane of (1) Scope, (2) Strength and (3) Awareness (McKnight \& Kashdan, 2009). Scope refers to how central the purpose is to one's life and to what extent it influences one's actions and thoughts across contexts. A broad scope would mean that the purpose would be more likely to influence behaviours across multiple conditions. Strength is the amount to which purpose actually influences actions, thoughts and emotions. A strong purpose would have a powerful influence on promoting relevant behaviours. Awareness is the extent to which the person is aware of and able to articulate their purpose. These elements of purpose influence each other and the degree to which one's purpose would influence behaviours. Promoting purpose may be achieved through intervening on each of these elements to impact how salient one's purpose is, how much it influences daily action and how well 
purpose can be articulated. For example, increasing one's awareness could influence the amount to which the individual was able to integrate behaviours from different contexts as relevant, and act in alignment with purpose driven goals.

\section{Qualitative reports}

These views on purpose as an overarching aim that directs behaviours and goals appear to match up with how lay people actually conceive the construct. In several studies, researchers have found that participants often define purpose with respect to (1) a foundation and direction for achieving one's aims, and (2) a mechanism for promoting happiness and resilience (Hill, Burrow, O’Dell, \& Thornton, 2010; Bronk, Finch, \& Talib, 2010; White, Wagener, \& Furrow, 2010). Furthermore, adolescents' would occasionally bring up themes of pro-social or occupational goals when describing purpose (Hill, et al., 2010).

\section{Purpose Exploration}

The discussion to this point has focused on the degree to which individuals have a sense of purpose or not. However, another element of the purpose development process is whether one is exploring life aims. Although pursuing a sense of purpose could be characterized by positive experiences, exploring or discovering a purpose may be a difficult or challenging experience, particularly later in life (Bronk et al., 2009). In a cross-sectional study of adolescents, emerging adults and adults, searching for purpose was more positively related to life satisfaction during adolescence and emerging adulthood than in the adult sample. That is, exploring a purpose may be particularly important for emerging adults, but may be an unpleasant experience for adults who have not yet found a purpose. It is valuable to assess purpose exploration, as it could be a way 
of finding purpose. Individuals that have not identified a purpose may develop a sense of purpose while exploring meaningful goals and actions.

Across all definitions, it remains clear that purpose is a higher-order aim that directs one's short- and long-term actions. Having a purpose can be beneficial to wellbeing, life satisfaction, and positive moods (as described in Chapter 3), but what can be done to either keep people focused on their ultimate aim for life, or to find one in the first place? In this series of studies, I will suggest a key may be mindfulness, given its clear conceptual link to the construct of purpose.

\section{Chapter 3: Comparisons between purpose and mindfulness}

Although the literature on mindfulness is rapidly accruing, one area that warrants greater consideration is how it differs from other 'positive' constructs. For instance, one potential correlate of mindfulness is purpose in life. While the literature has rarely discussed mindfulness and purpose in tandem, there are a number of similarities between the constructs.

\section{Religion}

For instance, one similarity between these constructs is that both have been encouraged by different religions. Several religious teachings encourage purpose or mindfulness as a path to freedom or salvation. Finding a purpose is often considered at the core of religion. In many religious faiths, purpose can be revealed or discovered through a life devoted to the religious teachings (McKnight \& Kashdan, 2009). Living virtuously may help individuals feel as though they are connecting to a higher source or gaining towards an important end, and in the process provide meaning and satisfaction (Warren, 2002). Similarly, "right mindfulness" is encouraged by the religious traditions 
of Buddhism and other contemplative traditions as element of the noble eightfold path to personal development (Baer, et al., 2004). As inferred by the word "right," Buddhist mindfulness requires a degree of ethical judgment, that is, the individual practices mindfulness with a particular attitude and orientation (Kang \& Whittingham, 2010). The qualities of mindfulness are emphasized as virtues in many philosophical and spiritual traditions for maintenance of well-being (Brown \& Ryan, 2003).

\section{Personality Correlates}

Mindful and purposeful people tend to exhibit a similar and generally positive profile of personality and well-being correlates. Both mindful and purposeful people tend to report higher levels of conscientiousness and lower levels of neuroticism (Siegler \& Brummett, 2000; Giluk, 2009). People high in neuroticism are sensitive to environmental stressors and are more likely to experience worry and irritability. Neuroticism is the personality trait most frequently investigated with mindfulness, and it has consistently demonstrated a negative relationship (Baer et al., 2006; Brown et al, 2007; Brown \& Ryan 2003; Giluk, 2009; Thompson \& Waltz, 2007). Neuroticism is moderately negatively related to purpose in life presumably because having a purpose enables people to organize and view their life in relation to their overall goals, which leads to less worry, depression and a sense that life is meaningless (Francis, et al., 2010; Robbins \& Francis, 2000; Siegler \& Brummett, 2000).

Both mindfulness and conscientiousness are characterized by self-discipline, the ability to self-regulate, and deliberate responding (Giluk, 2009). Furthermore, conscientiousness describes the qualities of person who is responsible, achievement oriented, and dependable (Mike, Harris, Roberts \& Jackson, under review). 
Unsurprisingly, conscientiousness is positively related to both purpose in life and mindfulness (Latzman, 2013; Siegler \& Brummett, 2000). Hallmarks of conscientiousness are self-discipline and achievement orientation, both of which may be apt descriptors of a person pursuing a life purpose. Similarly, the state of full attention to the present moment, seemingly descriptive of conscientious people is also emphasized in mindful attention and awareness (Kabat-Zinn, 2003). It may be that in order to be conscientious, one must be mindful of their internal and external environments.

\section{Coping}

Another similarity between mindfulness and purpose is the way they predict how individuals cope with stressors, a point demonstrated by examining the relative use of approach versus avoidance coping. Avoidance focused coping involves brining attention away from the stressor to reduce the negative experience through distraction, denial, mental disengagement, and alcohol or drug use (Lazarus \& Folkman, 1984). Avoidance focused coping is the opposite of experiential acceptance and actually often tends to exaggerate the feelings that one was trying to reduce (Carver, Scheier, \& Weintraub, 1989). Avoidant and repressive coping mechanisms may be effective for dealing with uncontrollable stressors, but they are related to decreased goal directed behaviour (Muraven, Collins \& Nienhaus, 2003). Approach focused coping involves orienting actions towards solving the problem at hand whether it is seeking social or emotional support, or planning next steps to take.

Purposeful and mindful people are both less likely to employ avoidant coping strategies and opt for approach coping mechanisms such as problem solving. Having a clearly defined aim can help maintain purpose-consistent behaviours when faced with 
obstacles, by allowing optimal allocation of resources (McKnight \& Kashdan, 2009). A purposeful person may be better able to remain focused on the task when faced with obstacles and would be less likely to engage in avoidant coping strategies. Approach motivated behaviours are higher in purposeful people, and involve strategies that lead toward purpose-related goals (McKnight \& Kashdan, 2013; Sheldon \& Houser-Marko, 2001). Having identified a purpose is theorized to help people perceive stressors as less threatening, because they would be able to interpret the situation in relation to their purpose and engage in more approached motivated actions (Baumeister, 1991; Kashdan \& McKnight, 2013).

Mindfulness also is related to greater use of approach coping strategies and reduced use of avoidant coping strategies (Grossman et al., 2004). Indeed, empirical work finds that mindfulness is linked to lower levels of experiential avoidance, avoidant coping, greater approach coping, higher well-being and less perceived stress in samples of undergraduate students (Thompson \& Waltz, 2010; Weinstein, Brown, \& Ryan, 2009). Mindful individuals may still experience negative thoughts, but by adopting an attitude of non-judgmental awareness, they are better able to disengage from the reaction and pursue a more beneficial strategy for solving the problem (Thompson \& Waltz, 2010).

\section{Flexibility}

Psychological flexibility is regarded as the ability of a person to adapt to situational demands, optimize mental resources and take multiple perspectives to balance competing desires (Kashdan \& Rotterburg, 2010). People high in psychological flexibility have the ability to realize potential options in present moment and adapt to the current demands by managing physical and psychological environments. This ability to 
take multiple perspectives may facilitate responding to the environment in adaptive rather than habitual ways and be able to predict and understand stress responses (Carver \& Scheier, 1998, Muraven \& Baumeister, 2000). Flexible individuals are able to respond with clarity and choose responses rather than being driven by habits or previous expectations.

Both purpose and mindfulness are related to higher levels of psychological flexibility. Mindfulness is related to increased cognitive, emotional and behavioural flexibility as it allows a gap between experiencing and responding to stimuli to allow the individual to respond in ways that optimally allocate mental resources (Shapiro, et al., 2006). Moreover, psychological flexibility has been defined as an element of purpose, meaning that purposeful people have the ability to flexibly navigate around obstacles (Kashdan \& McKnight, 2009). Not only are purposeful people able to recover from setbacks, they experience fewer psychological and physical problems than people without a purpose.

\section{Psychological and Affective Well-being}

Purpose and mindfulness are linked to religiosity, positive personality profiles, better coping habits, and a greater consideration for future consequences. As such, it is unsurprising that they also share one final commonality - a positive influence on emotional, psychological, and physical well-being. Having a purpose in life has been conceptualized as a part of psychological well-being (Ryff, 1989a; Ryff, 1989b). Purpose may be considered a mechanism for creating well-being, by directing actions towards meaningful goals that support one's life aim (Damon et al., 2003; Peterson, Park, \& Seligman, 2006; Ryff, 1989a). Furthermore, students are more likely to be satisfied with 
their life and less likely to experience negative affect if they have identified a purpose (Zika \& Chamberlain, 1992). Overall, quality of life, life satisfaction and happiness are positively related having identified a purpose in life (Ulmer, Range, \& Smith, 1991; French \& Joseph, 1999; Seligman, 2002).

Theories of mental health assume that a clear perception of reality is necessary for psychological adjustment, so it has been argued that mindfulness may encourage wellbeing through this vivid experience of life, coupled with an attitude of acceptance (Brown \& Ryan, 2003, Carver \& Scheier, 1998). Trait mindful awareness is associated with higher levels of life satisfaction, and higher levels of well-being (Brown \& Ryan, 2003; Carson \& Brown, 2005), though this relationship may be explained by a reduction of perceived life stress. In a sample comparing people with regular meditation practice to non-meditators, all facets of mindfulness (except for observe in non-meditators) were positively associated with Ryff's (1989b) measure of psychological well-being, which includes a subscale for purpose in life (Baer et al., 2008).

Another similarity between purpose and mindfulness is their relationships with positive and negative affect. Positive affect often involves a state of full concentration, where individuals are engaged and energetic, whereas negative affect is the extent to which someone feels unpleasant moods such as upset, anxiety, guilt or nervousness (Watson, Clark \& Tellegen, 1988). A state of full concentration and present moment experience is consistent with mindfulness, which often requires one to release from past issues or concerns. As such, it is unsurprising that trait mindfulness is related to lower negative affect, greater positive affect, and fewer depressive symptoms (Guilk, 2007). After an 8-week mindfulness intervention, participants showed a significant decrease in 
negative affect and increased positive affect (Schroevers \& Brandsma, 2010). Similarly, purpose in life is consistently related to greater positive affect and less negative affect (Zika \& Chamberlain, 1992; Damon et al, 2003). Purposelessness though is significantly related to negative affect and boredom (Fahlman et. al., 2009).

\section{Positive health outcomes}

Both mindfulness and purpose in life are related to higher ratings in overall physical well-being. Increases in mindfulness from clinical interventions have shown to be related to self-reported lower levels of chronic pain, increased sleep quality and increased relaxation (Baer, 2003; Brown \& Ryan 2003; Brown et. al., 2007; Grossman et. al, 2004; Caldwell, Harrison, Adams \& Quinn, 2010). In the same line, greater reports of purpose in life are related to self-reported physical health and well-being in undergraduate students (Thauberger, Ruznisky \& Cleland, 1981). Further reports of purpose reflect decreased pain and increased sleep quality, as well as less anxiety, depression and negative affect, stiffness and functional disability when recovering from knee surgery (Scheier et al., 2006; Smith \& Zautra, 2004; Ryff, Singer \& Love, 2004). For purpose, this influence on physical health even holds true when looking at objective markers of health, like mortality. Higher levels of purpose in life were related to longevity in a longitudinal sample of older adults, even when controlling for chronic health conditions, personality and mood symptoms and socioeconomic status (Boyle, Barnes, Buchman \& Bennett, 2009).

Across the multiple correlates between purpose and mindfulness, it is clear that the two constructs demonstrate similar qualities in predicting the way a person interacts with the world (coping mechanisms, flexibility of responding) and positive well-being 
outcomes. As these constructs have not been empirically studied in tandem, a theoretical justification for how mindfulness might influence one's sense of purpose will be outlined below.

\section{Chapter 4: Why Might Mindfulness Influence Purpose}

The following section explores possible reasons why mindfulness may influence feelings of purpose. Although there are multiple pathways by which mindfulness may influence purpose, the current series of studies will discuss and test three possible mechanisms (Figure 1). First, mindfulness may increase purpose through increasing of positive affect and promoting more flexible responding to stressors. Second, mindfulness may have an effect though the reduction of perceived stress and negative affect that may deter people from their purpose. Third, mindfulness may influence purpose through increasing mindfulness skills such as the ability to act with awareness, and articulate one's values, that may promote engagement in purpose-relevant daily activities. Each of these pathways is considered in turn.

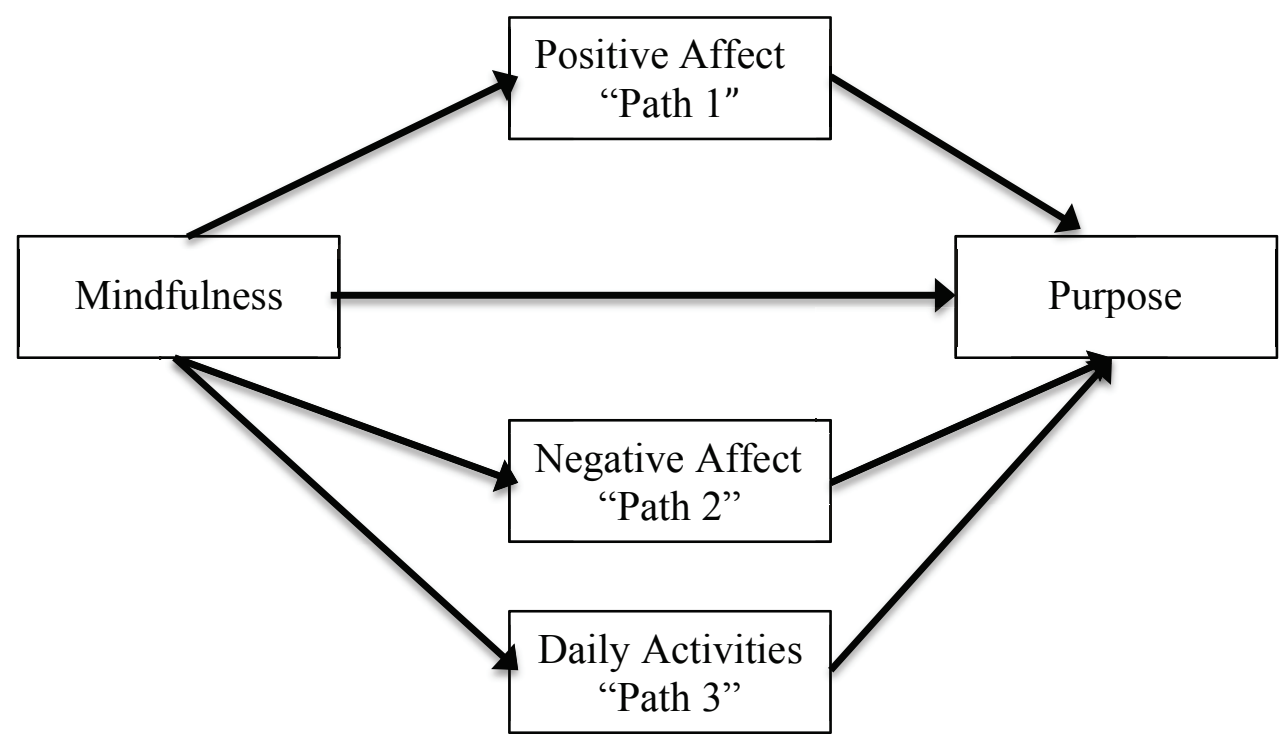

Figure 1. Three proposed pathways between mindfulness and purpose. 


\section{Pathway 1 - Increased Positive Affect}

One potential pathway by which mindfulness may influence purpose is through the broadening one's cognitive repertoire through increasing positive affect. It is possible that persons with a highly developed ability to act with awareness may stay in touch with contextual cues and readily available sources of positive reinforcement within their environment. By increasing the potential to experience positive emotions, one's resources for coping should increase according to the broaden-and-build theory of emotions (Fredrickson, 2001). Whereas the initial reaction to aversive stimuli with negative emotions may narrow possible stress responses to fight or flight responses, positive emotions can serve to widen the scope of one's awareness and increase the number of possible reactions available by increasing psychological and physical resources (Fredrickson, 2001). A mindful person may be better able to maintain their purpose because they experience greater positive affect. Experiencing positive emotions is related to increases in daily feelings of purpose (King, Hicks, Krull, \& Del Gaiso, 2006). The relationship between purpose and positive affect may be bi-directional. In a series of six studies, it was demonstrated that the strongest predictor of rating a day as meaningful was the degree of positive affect experienced that day (King et al, 2006). That is, positive mood may increase a person's sense of meaning because positive moods may increase awareness of the situation. Mindfulness may increase the individual's ability to broaden and build their positive resources, and decrease emotional reactivity.

\section{Pathway 2 - Reduced Negative Affect and Stress}

Another way that mindfulness may have an influence on purpose is through the reduction of stress and negative affect. When negative emotions, situations and thoughts 
occur, one may have greater difficulty with completing tasks and goals related to their purpose. An individual facing fewer perceived obstacles may be better able to remain committed to their values and goals. By having more resources to attend to potentially threatening stimuli or situations, the individual can focus their limited resources on achieving their goals. There is empirical evidence that experiencing negative affect after pursuing a goal serves to diminish goal pursuit (Aarts, Custers, \& Holland, 2007). By reducing negative affect or the reaction to negative affect, people might be more resilient in pursuing their goals.

Previous intervention studies on mindfulness have been effective at reducing levels of stress, anxiety and depression (Brown, Ryan, \& Creswell, 2007). One way mindfulness may reduce stress is through the reduction of physical and emotional reactivity to negative stimuli through developing the ability to accept rather than judge negative thoughts, feelings and sensations. Dispositional mindfulness may reduce stress and reactivity more directly through focused attention to one's sensory experience. In fact, mindful attention is related to lower experiential avoidance in undergraduate students with Post Traumatic Stress symptoms (Thompson \& Waltz, 2010). That is, mindful students less frequently used coping strategies that disengage them from their present experience (such as numbing the senses with drugs, or finding distractions). Indeed, in a sample of adolescents, less mindful individuals were particularly vulnerable to the negative effect of daily stress and rumination over the course of seven days (Ciesla et al., 2012). Individuals with greater attitudes of non-judgmental awareness and nonreactivity were less likely to experience negative mood and ruminate after a stressful event. 
Mindfulness may also influence appraisals of threats to one's purpose, that is, individuals that are more mindful would perceive stressors as less threatening, thereby increasing the resources available to flexibly respond to stressors. In relation to Lazarus and Folkman's (1984) cognitive model of coping with stress, mindfulness may influence both the primary appraisal of the stressor as less threatening, as well as the secondary appraisal of having adequate recourses to handle the situation. Mindful individuals would have a reduced emotional reactivity to negative stimuli, and greater perceived control to utilize adaptive coping strategies to handle future stressors (Wallace \& Shapiro, 2006).

\section{Pathway 3 - Daily Activities}

Mindfulness may influence purpose through increasing one's abilities to act with awareness and articulate their thoughts and emotions. First, by acting with awareness, individuals may be better able to regulate their daily goals and engage in activities that are aligned with their goals. Second, with an improved ability to describe one's thoughts and emotions, individuals may be better able to articulate and understand their ultimate directions for life.

Goal directed behaviour. One of the aims of mindfulness interventions is to enable the individual to act in a present state of bare awareness, rather than being driven by habitual patterns. A theoretical review of the mechanisms of mindfulness suggested that the act of intentionally attending to the present moment with nonjudgmental awareness creates a shift in perspective called "reperceiving" (Shapiro et al., 2006). It is through reperceiving the situation that leads to increases in self-regulation, value clarification, cognitive, emotional and behavioural flexibility and reduced reactivity to negative emotions and more goal directed behaviour. 
In line with this suggestion, research points to the potential for mindfulness to promote value-relevant action. The present moment awareness in mindfulness allows for objective evaluation of how current thinking is shaped by one's beliefs and behaviours and provides the opportunity for people to choose actions that are aligned with their values (Chambers, Lo \& Allen, 2008). A mindful person is able to regulate actions by choosing behaviours that are informed by their needs, values and feelings and is able to refrain from acting on tendencies that are undesirable. Not only should mindful individuals be more cognizant of how their current behaviours are shaped by past experiences, they may be better able to regulate and control their behaviour to better achieve their goals (Semple, Lee, Rosa, \& Miller, 2010).

An empirical study found that when acting mindfully, individuals act in ways that are more aligned with their values and interests (Brown \& Ryan, 2003). People who score higher on measures of mindfulness demonstrate greater self-regulated emotion and act in ways that fulfill their interests and values (Shapiro et al., 2006). Mindfulness is thought to encourage responding in ways that are consistent with one's values, goals and needs rather than reacting in terms of habits, overlearned responses or reactions to situational cues (Leary, Adams \& Tate, 2006). Mindfulness can also lead to the engagement and completion of specific tasks by disengaging from thoughts about task completion, which can increase anxiety and other emotions that can disrupt performance.

Articulating values. Another reason why increasing mindful skills would influence purpose is that being able to describe inner thoughts and feelings may keep people focused on what is valuable to them because they are better able to articulate those values. As stated previously, awareness is an important dimension of purpose (Kashdan 
\& McKnight, 2009). Developing a purpose requires introspection, planning and developing insights (Carver \& Scheier, 2002). As such, mindfulness can be a context for self-development by understanding where one is, and how it is different from where one would like to be (Greeson, 2009; Hirst, 2003). For instance, in Acceptance and Commitment Therapy (ACT), mindfulness is used as a tool for individuals to accept the present moment, and to keep on track with goal directed behaviours (Hayes, Strosahl \& Wilson, 1999). By having an understanding of the current situation, one's abilities and what is not achievable, mindful people may be better able to choose actions that are aligned with their values.

\section{Summary}

While there are many potential mechanisms by which mindfulness may influence a sense of purpose or daily purpose related activities, the current studies seeks to address three potential possibilities (Figure 1). First, purpose may be influenced through the building of positive emotions that leads to greater pursuit of purpose and flexible resource allocation. Second, mindfulness may influence purpose through the decrease of negative affect and stress. Finally, mindfulness may influence purpose through the clarification of goals and ability to articulate one's purpose.

\section{Chapter 5: Daily Purpose Fluctuation}

The degree to which one feels life has a purpose, and they are committed to that purpose can fluctuate both over the lifespan and at a daily level, and the current series of studies sought to understand what behaviours influence these changes. Across the lifespan, one's stated purpose appears to remain stable or decline slightly from adolescence into adulthood (Hill, Burrow, Brandenberger, Lapsley, \& Quaranto, 2010). 
However, in middle adulthood, a meta-analysis of age differences for 70 studies showed that adults decline in purpose (Pinquart, 2002). While these studies show that a sense of purpose can fluctuate across the life course, more recent research has begun to demonstrate changes in purpose at a more micro level. It is valuable to assess these constructs on a daily level to understand what the daily lives of purposeful people look like, and how they differ from those without purpose. Further, how daily behaviours and moods influence one's commitment to purpose will provide valuable insight for interventions to increase purpose at a daily level.

\section{Daily purpose}

In a sample of Asian American adolescents, participants wrote about their daily activities, stress, purpose, school activities and interactions with family members (Kiang, 2012). A daily diary methodology was utilized to assess which events and activities are related to a daily sense of purpose. Overall, their results demonstrated that purpose fluctuates on a daily level as a function of daily activities related to helping family members and fulfilling family roles. Engaging in leisure activities was negatively related to daily levels of purpose. Building from previous research on purpose and well-being, this study provided evidence that daily feelings of purposefulness can contribute greater well-being and lower anxiety; interestingly, results also show that the types of daily activities that may contribute to these effects.

Given that daily activities can influence one's sense of purpose, it would be beneficial to examine if engaging in specific types of daily activities would influence one's ability to develop and maintain a purposeful life (Kiang, 2012). Researchers have begun to address the specific activities and environments that foster purpose. To 
determine which activities are related to a sense of purpose and well-being, it is essential to know the type of life aim endorsed. Four general orientations of purpose have been identified including pro-social aims (helping others), financial or occupational aims (successful entrepreneur), creative aims (original artistic work) and personal recognition aims (authority in the field) (Hill et al., 2010). Whereas people from collectivist cultures may be more likely to endorse pro-social aims and find helping others meaningful, people from individualistic cultures may adopt more occupational or personal recognition aims and find advancement in career objectives meaningful (Kiang \& Fuligni, 2010).

Understanding how to best promote purpose through daily activities would provide valuable insight into how people maintain a sense of purpose and if this reflects the benefits of purpose on a day-to-day level. In the current series of studies, to get at how daily activities fluctuate and influence other well-being indices, participants reported on the number of minutes spent in daily activities associated with previously identified categories of purpose orientations such as pro-social activities (volunteering time), financial activities (saving for the future), and creative activities (creating artistic work) (Hill et al., 2010). By using activities that are known to be related to identified purpose orientations, the current series of studies was able to test whether people are engaging in behaviours previously linked to some of the more common purposes set by college students. The amount to which an individual reports well-being and a sense of purpose may not only be related to the activities they engage in but also be related to the amount to which they are engaged and attentive to these experiences. Mindfulness may be a missing link in explaining daily fluctuations in purpose. 


\section{Chapter 6: Current Studies}

Prior to daily level examination, research first is needed to connect purpose and mindfulness. Purpose and mindfulness should be positively correlated because the constructs share correlates with respect to well-being, personality traits and mood. In two studies, purpose, mindfulness and well-being were assessed with online studies. In Study 1, students at Carleton University completed the Youth Purpose Scale (Bundick et al., 2006), a multi-faceted measure of mindfulness, and indicators of well-being (affect and life satisfaction). The purpose of the first study was to empirically link purpose and mindfulness, and determine how they predict well-being outcomes. It was anticipated that purpose would be associated with overall mindfulness, and that these constructs would differentially predict well-being outcomes. Testing the independence of both constructs to predict well-being is important to demonstrate that they are related and not synonymous. In Study 2, the findings were replicated in an online adult sample, with alternate measures of purpose as well as assessments of perceived stress. In both Study 1 and 2, exploratory mediation models were tested as preliminary support for the claim that mindfulness may influence purpose through its effects on stress, negative affect and positive affect.

\section{Study 1}

\section{Method}

\section{Participants}

One hundred seventy-nine undergraduate students at enrolled at Carleton University completed an online survey in exchange for course credit. The sample was 
predominantly female $(77 \%)$, between the ages of 18 and $21\left(80 \%, \mathrm{M}_{\mathrm{age}}=20.7\right.$ years, $\mathrm{SD}$ $=4.57)$ and White $(66 \%)$.

\section{Procedures and Materials}

Youth Purpose Scale. Purpose commitment and purpose exploration was assessed using the Youth Purpose Scale (Bundick et al., 2006), which was designed for use with adolescent and emerging adult samples, compiling items from existing surveys (Crumbaugh \& Maholick, 1967; Keyes, Shmotkin, \& Ryff, 2002; Steger, Frazier, Oishi, $\&$ Kaler, 2006). Participants rate their agreement with each item on a scale from 1 (Strongly Disagree) to 7 (Strongly Agree). Fifteen items were used to assess commitment to one's purpose including items such as "My life has a clear sense of purpose" and "I rarely do anything that feels purposeful to me" $(\alpha=.91)$. The exploration of one's purpose was rated with five items, including "I am always looking to find my life's purpose" and "I am always searching for something that makes my life feel significant" $(\alpha=.86)$.

Life Satisfaction. As an indicator of well-being, life satisfaction was assessed using the Satisfaction with Life Scale (Diener, Emmons, Larsen, \& Griffin, 1985). Participants completed the five-item scale by rating items on a seven-point scale from 1 (Strongly Disagree) to 7 (Strongly Agree). An example of an item on this scale is "In most ways my life is close to ideal." $(\alpha=.89)$.

Positive and Negative Affect. The most widely used measure of positive and negative affect is the Positive and Negative Affect Schedule (Watson et al., 1988). Participants rate the extent to which they tend to experience each of the emotions on a scale from 1 (Very slightly or not at all) to 5 (Extremely). Positive affect is assessed with 
10 items, with emotions such as "Interested" and "Alert" $(\alpha=.89)$ Negative affect is assessed with 10 items with items such as "Distressed" and "Upset" $(\alpha=.89)$.

Mindfulness. Mindfulness was assessed using the Five Facet Mindfulness Questionnaire (FFMQ; Baer et al., 2006), which assesses five facets of a general tendency to be mindful in everyday life. The 39 items were derived from a large factor analytic study of previous mindfulness scales. The observe facet is assessed with eight items, including "I notice the smells and aromas of things" $(\alpha=.79)$. Describing internal experiences is assessed with eight items including, "I'm good at finding the words to describe my feelings" $(\alpha=.88)$. Acting with awareness is assessed with eight items including "I find my self doing things without paying attention" (reverse scored, $\alpha=.84$ ). Non-judging is assessed with eight items, including "I tell myself that I shouldn't be feeling the way I'm feeling" (reverse scored, $\alpha=.89$ ). Non-reactivity is assessed with seven items, including "I watch my feelings without getting carried away by them" $(\alpha=$ .62). Each item is rated on a 5-point scale with scores ranging from 1 (Never or Very Rarely True) to 5 (Very Often or Always True). An overall level of dispositional mindfulness is assessed with a total sum of all of the scales, with higher total scores indicating greater dispositional mindfulness $(\alpha=.85)$. For the mediation analyses, the overall construct of mindfulness was tested to reduce the number of analyses, and because there is not substantial evidence to support individual factors being related to each of the proposed pathways.

\section{Results}

Congruent with expectations, mindfulness and purpose in life were strongly related to both each other and to indicators of well-being (Table 1 for all study 
correlations). The individual facets of mindfulness showed a distinct pattern of relation with purpose. As expected, the facets of acing with awareness $(r=.36, p<.01)$, describing one's thoughts and emotions $(r=.47, p<.01)$ and being non-judgmental of one's inner experiences $(r=.23, p<.01)$ were most strongly related to one's commitment to their purpose. Interestingly, the mindful skill of being able to observe one's internal and external environment was not related to purpose commitment $(r=.11$, $p<.01)$ but was the only facet related to purpose exploration $(r=.34, p<.01)$.

It is expected that mindfulness would reduce emotional reactivity causing people to report a greater sense of purpose in life (Figure 2). Two tests of the mediational pathways between mindfulness predicting purpose were explored with possible mediators including: (1) a reduction in negative affect, (2) an increase of positive affect (Figure 1). To test the hypothesized mediating effects, a bootstrapping approach was performed using a macro for SPSS (Preacher \& Hayes, 2004). Using 5000 resamples, the indirect effects were tested using bootstrap 99\% confidence intervals (Table 2). All variables were approximately normally distributed, the relationship between the predictor and the criterion variables were linear, and the assumption of homoscedasticity was met. There were no significant outliers.

First, negative affect was a significant mediator in the relationship between mindfulness and purpose $(99 \% \mathrm{LL}=.0119, \mathrm{UL}=.0233$; Table 3$)$. Second, positive affect also significantly explained the relationship between mindfulness and purpose $(99 \% \mathrm{LL}=$ $.0037, \mathrm{UL}=.0142)$. However, as shown in Table 3 , the direct effect of mindfulness on purpose remained significant in all cases, suggesting each was only a partial mediator. 
Hierarchical multiple regression analyses were conducted to test effect of mindfulness on well-being when controlling for purpose commitment. Multiple regression analyses demonstrated that overall mindfulness is a unique predictor of life satisfaction $(b=.17)$ even when controlling for purpose commitment $\left(b=.49 ; \mathrm{R}^{2}=.36\right)$.

\section{Study 2}

In Study 2, the findings were replicated with a larger sample of adults completing an online survey. Furthermore, the previous study was extended by utilizing more commonly employed measures of purpose, as well as negative indicators of well-being such as perceived life stress. Mediational models were tested to address if the relationship between mindfulness and purpose was explained by perceived stress, negative affect and/or positive affect.

\section{Method}

\section{Participants}

Three hundred twenty-four participants took part on an online MTurk survey in return for $\$ 0.50$ compensation. Data integrity questions were included throughout, and seventeen participants were eliminated for failing to correctly answer these checks. Of the final 307 participants, most were female (65\%), White $(75 \%)$, born in the United States (90\%) and currently living there (96\%), and had attained a level of education greater than a high school diploma $(90 \%)$, and were on average 35.3 years of age (range 18 to 73 years, $\mathrm{SD}=13.16$ ). With respect to relationship status, $45 \%$ reported being currently married or in a long-term committed relationship, $32 \%$ were single, and $10 \%$ were single, divorced or widowed.

\section{Procedure and Materials}


Purpose. Participants completed two measures of purpose frequently employed with adult samples. First, the Life Engagement Test (Scheier et al., 2006) is a six-item measure that includes items such as "To me, the things I do are all worthwhile" $(\alpha=.87)$. Second, the Ryff Psychological Well-being Scale (Ryff, 1989; Ryff \& Keyes, 1995) is a nine-item measure including items such as "Some people wander aimless through life, but I am not one of them" $(\alpha=.84)$.

Well-being. Well-being was assessed using three different indices. Life satisfaction $(\alpha=.93)$ positive affect $(\alpha=.91)$, and negative affect $(\alpha=.93)$ were assessed using the same measures as Study 1.

Mindfulness. A brief version of the FFMQ used in Study 1 was used with 24 items assessing the five facets of mindfulness rather than 39 (Bohlmeijer, ten Klooster, Fledderus, Veehof, \& Baer, 2011). Both the overall scale $(\alpha=.87)$ and each subscale showed adequate internal reliability (describe $\alpha=.86$, non-react $\alpha=.81$, non-judge $\alpha=$ .83 , observe $\alpha=.77$, aware $\alpha=.87$ ).

Stress. Stress was assessed using a short four-item version of the Perceived Stress Scale (Cohen, Kamarck, \& Mermelstein, 1983). Participants are asked to report how frequently in the past month they have felt a certain way from 1 (Never) to 5 (Very Often). A sample item is "In the past month, how often have you felt that you were unable to control the important things in your life" $(\alpha=.83)$.

\section{Results}

Positive correlations were found between mindfulness and both measures of purpose (see Table 2). The findings were similar across Study 1 and 2 with all mindfulness facets positively relating to purpose except for the facet observe. To 
replicate and extend the findings from Study 1, the first two meditational pathways were tested and stress was included as a third potential mediator for this relationship. The three meditational pathways tested were (1) through a reduction of stress, (2) a reduction in negative affect, (3) increase in positive affect. As described in Study 1, a bootstrapping approach was used to test the indirect effects.

First, stress was a significant mediator in the relationship between mindfulness and purpose $(99 \% \mathrm{LL}=.0119, \mathrm{UL}=.0233$; Table 3$)$. Second, negative affect also significantly explained the relationship between mindfulness and purpose $(99 \% \mathrm{LL}=$ $.0037, \mathrm{UL}=.0142)$. Third, positive affect also was a significant mediator between mindfulness and purpose $(99 \% \mathrm{LL}=.0024, \mathrm{UL}=.0105)$. However, as shown in Table 3, the direct effect of mindfulness on purpose remained significant in all cases, suggesting each was only a partial mediator.

\section{Intermediate Summary}

In two studies, findings showed that mindfulness was positively related to purpose, and that both constructs are related to indicators of well-being. Moreover, in Study 1, mindfulness and purpose uniquely predicted markers of wellbeing such as satisfaction with life. Furthermore, mediation models demonstrated the effect of mindfulness on purpose is partially explained by positive affect and negative affect. In Study 2, mediation models were tested to examine why mindfulness may be related to one's sense of purpose (see Figure 2). The relationship between mindfulness and one's sense of purpose was partially mediated by each stress, negative affect and purpose in life. Although these studies provide insights into aspects of purpose, a convincing causal argument of mindfulness influencing purpose cannot be made with the current cross- 
sectional design. Studies 1 and 2 though provide a valuable foundation for testing predictions regarding the potential role of mindfulness to understand one's feelings of purpose and commitment to purpose.

Study 3 thus intervenes on mindfulness to determine if daily purpose commitment and a sense of purpose are related to increases in mindfulness skills. Intervening on mindfulness provides further evidence of how mindfulness and purpose are related, and furthers our understanding of why both a sense of purpose and one's commitment to purpose can fluctuate on a daily level. Furthermore, perceived stress, positive affect, and negative affect may play an important role in both one's commitment to purpose and choice of daily activities. Study 3 helped determine how the cognitive mindsets and attitudes associated with mindfulness influence purpose, well-being and daily activities. 
Table 1: Correlations between mindfulness, purpose commitment and exploration in Study 1.

\begin{tabular}{|c|c|c|c|c|c|c|c|c|c|c|c|}
\hline & $\begin{array}{l}\text { Total } \\
\text { Mindfulness }\end{array}$ & Observe & Describe & $\begin{array}{l}\text { Act } \\
\text { Aware }\end{array}$ & NonJudge & NonReact & $\begin{array}{l}\text { Purpose } \\
\text { Commit }\end{array}$ & $\begin{array}{l}\text { Purpose } \\
\text { Explore }\end{array}$ & SWLS & PA & NA \\
\hline Total & - & & & & & & & & & & \\
\hline Mindfulness & & & & & & & & & & & \\
\hline Observe & $.31 *$ & - & & & & & & & & & \\
\hline Describe & $.70 *$ & .16 & - & & & & & & & & \\
\hline Act Aware & $.75 *$ & -.04 & $.39 *$ & - & & & & & & & \\
\hline Non Judge & $.43 *$ & -.34 & .13 & $.54 *$ & - & & & & & & \\
\hline Non React & $.46^{*}$ & $.21 *$ & $.21 *$ & .12 & .09 & - & & & & & \\
\hline Purpose & $.51 *$ & .14 & $.47 *$ & $.36^{*}$ & $.23 *$ & $.20 *$ & - & & & & \\
\hline Commit & & & & & & & & & & & \\
\hline Purpose & -.03 & $.35^{*}$ & .01 & -.11 & $-.27 *$ & .04 & .04 & - & & & \\
\hline Explore & & & & & & & & & & & \\
\hline SWLS & $.43 *$ & .02 & $.33 *$ & $.36^{*}$ & $.29 *$ & .16 & $.58 *$ & -.10 & - & & \\
\hline PA & $.54^{*}$ & .12 & $.43 *$ & $.46^{*}$ & $.28^{*}$ & $.23 *$ & $.67 *$ & .02 & $.58 *$ & - & \\
\hline NA & $-.53 *$ & .12 & $-.36 *$ & $-.45^{*}$ & $-.51 *$ & $-.21 *$ & $-.38 *$ & .06 & $-.46^{*}$ & $-.36 *$ & - \\
\hline
\end{tabular}

Note. ${ }^{*}$ significant at $p<.05 . \mathrm{SWLS}=$ Satisfaction with life scale, PA = Positive affect, NA = Negative affect. 
Table 2: Testing mediator effects of stress, negative affect and positive affect using bootstrapping in Study 1

\begin{tabular}{|c|c|c|c|c|}
\hline \multirow[t]{2}{*}{ Mediator } & \multicolumn{2}{|c|}{$\begin{array}{c}\text { Indirect Effect } \\
99 \% \text { CI }\end{array}$} & \multirow{2}{*}{$\begin{array}{c}\text { Direct Effect (c) of } \\
\text { mindfulness on purpose } \\
\text { t-test }\end{array}$} & \multirow{2}{*}{$\begin{array}{l}\text { Direct Effect (c') } \\
\text { controlling for mediator } \\
\text { t-test }\end{array}$} \\
\hline & LL & UL & & \\
\hline & & & $7.92 *$ & \\
\hline Negative Affect & -.0258 & .1881 & & $5.76^{*}$ \\
\hline Positive Affect & .1966 & .4330 & & $3.26^{*}$ \\
\hline
\end{tabular}

Note. ${ }^{*} p<.05$. Age and gender were included in the analyses as controls. Purpose is measured using the Life Engagement Test. 
Table 3: Correlations between mindfulness, purpose and indicators of well-being in Study 2.

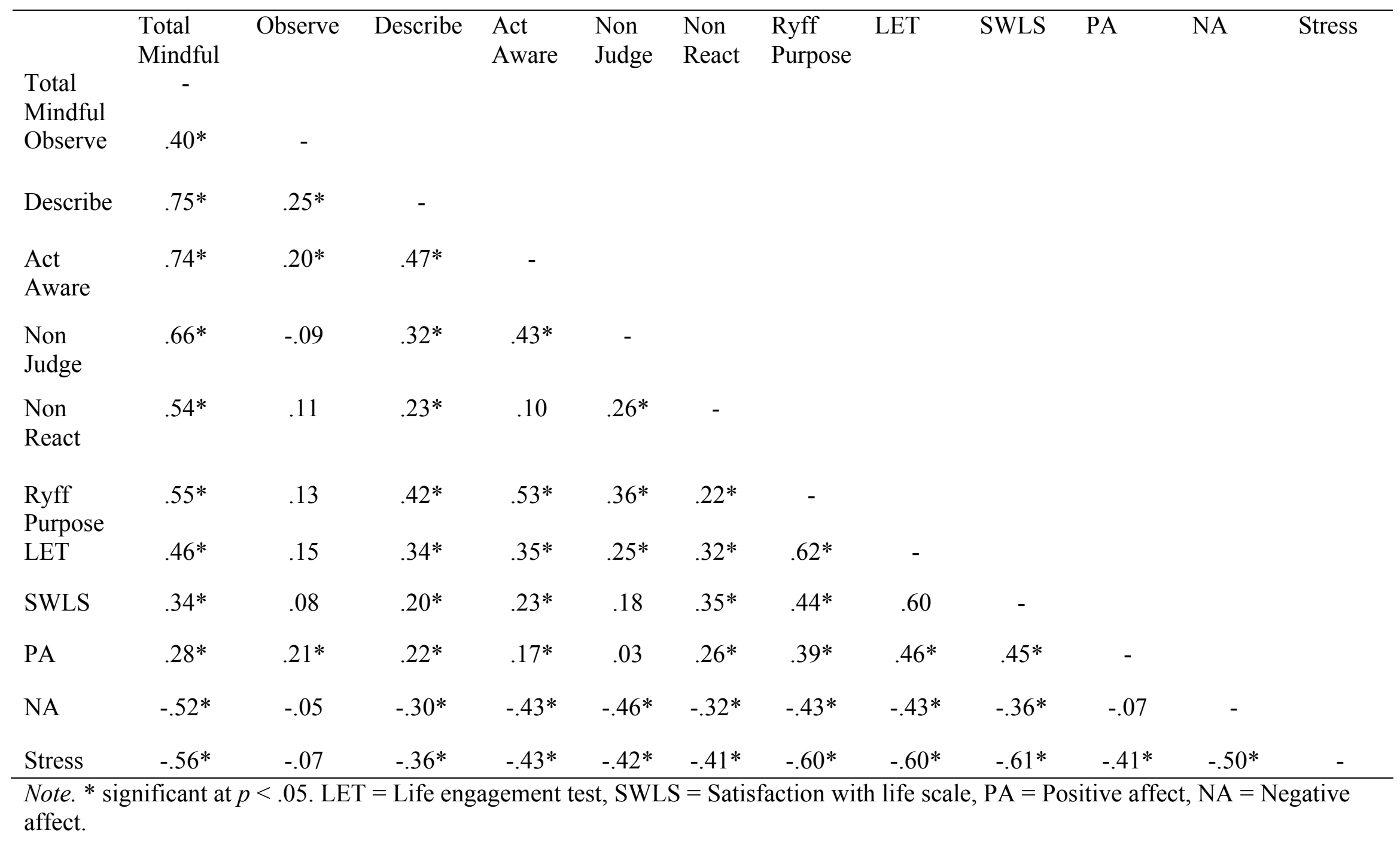


Table 4: Testing mediator effects of stress, negative affect and positive affect using bootstrapping in Study 2

\begin{tabular}{|c|c|c|c|c|}
\hline \multirow[t]{2}{*}{ Mediator } & \multicolumn{2}{|c|}{$\begin{array}{c}\text { Indirect Effect } \\
99 \% \mathrm{CI}\end{array}$} & \multirow[t]{2}{*}{$\begin{array}{l}\text { Direct Effect (c) of } \\
\text { mindfulness on purpose }\end{array}$} & \multirow{2}{*}{$\begin{array}{l}\text { Direct Effect (c') } \\
\text { controlling for mediator } \\
\text { t-test }\end{array}$} \\
\hline & LL & UL & & \\
\hline & & & $8.97 *$ & \\
\hline Stress & .0119 & .0233 & & $3.28 *$ \\
\hline Negative Affect & .0037 & .0142 & & $5.56 *$ \\
\hline Positive Affect & .0024 & .0105 & & $7.32 *$ \\
\hline
\end{tabular}

Note. ${ }^{*} p<.05$. Age and gender were included in the analyses as controls. Purpose is measured using the Life Engagement Test. 
Figure 2. Mediation model in Studies 1 and 2.

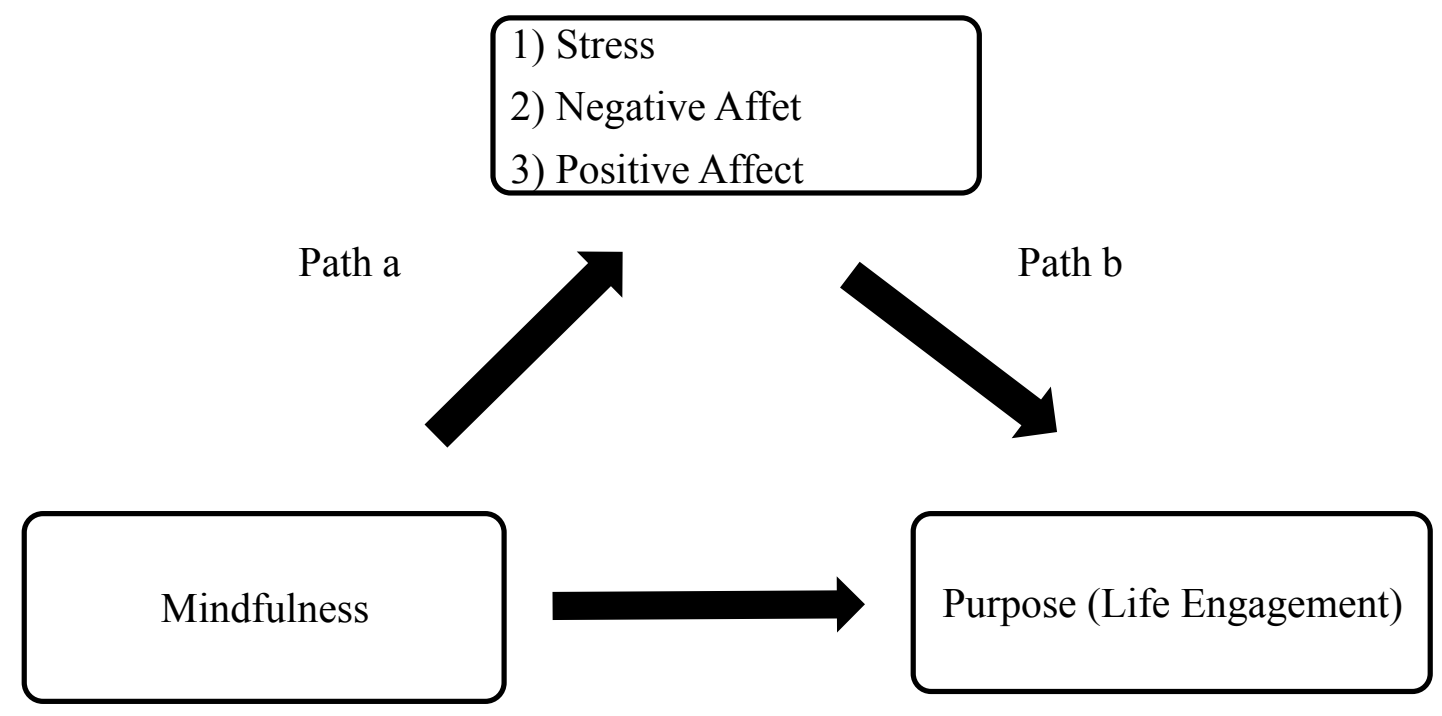

Path c: Direct Effect

Path c': Indirect

Effect with mediator

in equation. 


\section{Chapter 7: Study 3}

The goal of Study 3 is to determine whether and how being mindful can influence purpose, well-being and daily activities. Studies 1 and 2 suggested that mindfulness might have an influence on having a sense of purpose. As outlined in previous sections, the third study explored three possible mechanisms through which mindfulness may have an effect on purpose (Figure 1). Mindfulness may influence purpose through (1) building positive emotions that enable flexible responding to stressors, (2) the reduction of perceived stress and emotional reactivity to stress and/or (3) increasing the ability to engage in activities with awareness, coupled with an attitude of acceptance and nonreactivity to setbacks which help maintain commitment to purpose. To test these pathways, Study 3 employed a brief one-week online intervention of everyday mindfulness behaviours. A prospective daily diary methodology was utilized to examine positive affect, negative affect, stress, and daily activities as potential mediators between mindfulness and daily fluctuations in purpose. The design of Study 3 allowed a better test of the causal argument that increases in mindfulness are related to daily purpose and overall purpose commitment. Because mindfulness and purpose are theorized to be valuable attributes, greater levels of both were hypothesized to promote greater wellbeing across each study. Study 3 sought to address six primary research questions outlined in italics below.

Does intervening on mindfulness skills increase dispositional mindfulness?

It is expected that the participants in the intervention condition would have greater levels of dispositional mindfulness from pre-test to post-test when compared to the control group. Answering this question will advance the mindfulness literature twofold. 
First, the brief intervention of informal mindfulness skills provides a unique online assessment of mindfulness skills in daily life, which will allow for broad access to the program without needing a clinician. Second, the mindfulness intervention allowed the assessment of which components of mindfulness training have an effect, by assessing only informal meditation techniques. The mindfulness literature often utilizes formal meditation techniques in tandem with informal ones (Kabat-Zinn, 2003) so it is unclear whether informal techniques alone are enough to produce a meaningful effect. The design of Study 3 provides an important step towards separating the effects of meditation from one's daily experiences of acting mindfully.

\section{Influencing Purpose Commitment and Daily Activities}

Commitment to purpose is operationalized as the degree to which someone feels his or her life has a clear and satisfying life purpose. Commitment to purpose thus involves a sense of beliefs, values and the ability to take steps towards achieving one's purpose. A sense of commitment to purpose can fluctuate over the week (Kiang, 2010). Whereas one's purpose (i.e., the broader goals they are pursuing) remains stable over time, on a daily level the amount to which the individual feels as though their life is imbued with purpose or make effort towards their purpose, may fluctuate depending on daily events and moods.

Do purposeful people engage in more purpose related activities? How do these daily activities influence one's purpose commitment?

The use of a daily diary approach advances the purpose literature by assessing how fluctuations of daily purpose commitment are associated with day-to-day activities, mood, rumination and perceptions of stress. The daily assessment of purpose and the 
activities that may coincide with one's purpose aims will provide an important understanding of a) whether purposeful people report more purpose-relevant activities on a daily level, and b) whether the daily activities engaged in lead to greater levels of trait level purpose.

What is the influence of mindfulness on purpose?

The design of Study 3 provided an opportunity to examine how mindfulness influences daily purpose, stress and activities in both individuals and between treatment groups. It furthers the mindfulness literature because it is the first study to determine how a daily mindfulness intervention influences daily levels of purpose, activities, stress, mood, and life satisfaction.

Is the relationship between mindfulness and purpose explained by an increase in positive affectivity?

Study 3 sought to further understand the causal mechanisms that underlie the relationship between mindfulness and purpose. Path 1 (Figure 1) was tested to determine whether mindfulness influences purpose is through an increase in positive affect.

Assessing this pathway provided evidence whether daily mindfulness activities influence daily positive affect.

Does increasing positive affect or decreasing negative affect directly influence purpose?

Study 3 utilized an active control group to determine whether increasing positive affect through journal writing influences one's purpose commitment, or goal-relevant behaviours. Testing the significance of this pathway provides an empirical test of the broaden-and-build theory of positive emotions in the stress process (Fredrickson, 2001), implying that making people feel good may help them pursue or remain committed to 
purpose. Increased mindfulness is related to decreases in negative affect and perceived stress (Cavanagh, et al., 2013). Path 2 (Figure 1) tests whether stress and negative affect influence daily purpose, and if increases in mindfulness help to attenuate the experience of negative affect from stressors.

\section{Participants}

\section{Method}

Participants were recruited from Carleton University and Algonquin College to gain a broader sample of emerging adults with a more diverse range of goals and purpose intentions rather than using exclusively Carleton students. For web-based brief mindfulness interventions, medium effect sizes have been reported (between $d=.50$ .70) with 25 participants apiece in treatment and wait-list control groups (Gluck \& Macker, 2011). Participants were compensated $\$ 5$ each for the completion of pre/post measures, and $\$ 2$ per day for each of the 5 days completed, for a grand total of $\$ 20$ if all surveys were completed. In recruitment and the informed consent, the importance of completing both tasks for the day on time was emphasized. The morning questionnaires were sent out at $6 \mathrm{am}$ and were only considered valid if completed by $12 \mathrm{pm}$. The evening questionnaires were sent out at 5pm and were only counted as valid if they were completed before $12 \mathrm{am}$. It was stated in the emails and recruitment notices that to receive full compensation for the study each of the daily tasks must be completed. Participants were explicitly told about the future required tasks and compliance checks are included in the assessments to ensure engagement with the tasks.

A total of 87 participants completed the initial baseline survey, but 65 were kept in the final analysis because they completed both baseline and post test data (74\% Carleton students). Participants were randomly assigned to either the mindfulness 
condition $\left(\mathrm{N}=35 ; \mathrm{M}_{\mathrm{age}}=21.32, \mathrm{SD}=3.01 ; 51.4 \%\right.$ Female, White $(31.4 \%)$, Asian/AsianCanadian (28.6\%), or African-Canadian/Black (22.9\%) or the control condition. The control group was of comparable age $\left(\mathrm{N}=30 ; \mathrm{M}_{\mathrm{age}}=21.3, \mathrm{SD}=3.86\right)$, gender $(63.3 \%$ Female) and racial/ethic backgrounds (53.3\% White, 16.7\% Asian/Asian-Canadian, 10\% African-Canadian/Black).

\section{Procedure}

The study was advertised on the campuses of Carleton University and Algonquin College, and told participants to email or call if they wish to enroll in the study. All participants were given informed consent forms and complete demographics and pre-test questionnaires online, hosted by the Qualtrics online survey platform (Appendices A K). Within 24 hours of completing the pre-test questionnaires, participants were randomized into the intervention or control group, using a computer generated blocked random allocation method. Figure 3 provides a consort diagram of the study procedures. The intervention lasted five days and participants were emailed twice a day, in morning and in the evening. Participants continued to be sent the surveys even if they missed a day. The morning after the final day of the intervention, participants were emailed with the post-intervention questionnaires and given debriefing forms. Data collection occurred over the course of four consecutive weeks in the winter starting on Sunday and finishing on the next Saturday.

\section{Treatment conditions}

Intervention Condition. Each morning, for five days, participants in the mindfulness condition were asked to write brief journal entries designed to teach mindfulness skills (see Appendix Q for daily prompts). The exercises were adapted from 
the Mindfulness-Based Stress Reduction Workbook (Stahl, Goldstein \& Kabat-Zinn, 2010) and other mindfulness based stress reduction, and daily online meditation resources (taken from Fronsdal, 2010). Each morning, participants were given an experiential task, and then asked to set an intention based on the exercise to complete throughout the day. On a separate screen, participants were asked to describe what their assigned exercise was for the day as a way to ensure a minimum level of engagement with the assigned task.

Each evening, for five days, participants were emailed and asked to complete the evening questionnaires. First, to assess participants' compliance with the study procedures, they were asked to describe the task they were assigned that day, and to rate the amount to which they engaged in that activity throughout the day on four point scale. All participants were then reminded of the daily activity and were asked to describe their experience with completing or not completing this homework throughout the day. Next, participants completed a brief series of questionnaires assessing their purpose, moods, and daily activities (Appendices L - P). On the seventh day (post-test assessment) participants were given the same pre-test post-test questionnaires and debriefing forms.

Control Condition. It is an important advance over previous studies that include a waitlist control or no-participant control to have an active control group to account for the daily delivery of technology and any positive effects of treatment expectation. Furthermore, to test the prediction that purpose may be influenced by increases in positive affect, and to control for any effects of journaling and reporting of one's daily events, the active control condition for Study 3 included an element of positive journal writing. To distinguish between the mindfulness intervention and therapeutic benefits of 
journal writing (see e.g., Pennebaker \& Seagal, 1999), the control group was given a positive event about which to write (Appendix R). Writing about positive events is related feeling happier and reporting fewer depressive symptoms (Seligman, Steen, Park \& Peterson, 2005). Participants were emailed every morning with an affirmation and asked to engage in a brief journal writing exercise. In contrast to the mindfulness intervention, participants in the control condition were not given explicit instruction or encouragement regarding how to implement the behavior in daily life. Each evening, participants completed follow-up questionnaires.

\section{Materials}

Pre-test

Demographics. Basic demographic information was collected pre-intervention to assess participant's age, basic background information, and additional questions relevant to the study to control for as potential moderators of the effects of the intervention (Appendix A).

Mindfulness. The Five Facet Mindfulness Questionnaire was administered as outlined in Study 1 with items adapted to reflect "in the past week" rather than "in the past six months" to maintain congruence from pre-to- post-test (Appendix B). The 24item short from was used $(\alpha=.86)$ to maintain participant engagement and reduce potential for fatigue.

Purpose. To assess the amount to which one is exploring their purpose, five items from the Youth Purpose Scale (Bundick et al., 2006; Appendix C) were administered ( $\alpha=$ .90) as described in Study 1. To assess a sense of purpose, the 6-item Life Engagement Test (Scheier, et al. 2006) was assessed as in Study 2 (Appendix D, $\alpha=.80$ ). Change 
scores were calculated to assess fluctuations in one's sense of purpose from pre-test to post-test. Whereas the study of change should ultimately include at least three measurements, the use of change scores with only two time points provides a preliminary and defensible strategy for looking at change (see e.g., Turiano, Pitzer, Armour, Karlamangla, Ryff, \& Mroczek, 2013).

Life Satisfaction. As outlined in Study 1, the Satisfaction with Life Scale was administered ( $\alpha=.89$; Diener, et al, 1985; Appendix H).

Perceived stress. Perceived stress was measured with the 10-item Perceived Stress Scale adapted for daily levels of stress experienced in the past week as outlined in Study 2 with the wording adapted to reflect their moods that day rather than thinking back to earlier in the week $(\alpha=.90$; Cohen, Kamarck \& Mermelstein, 1983; Appendix I).

Rumination. Rumination was assessed using the 22-item Ruminative Response Scale (RRS; Treynor et al., 2003; Appendix J) of the Response Styles Questionnaire (RSQ, Nolen-Hoeksma \& Morrow, 1991). This scale assesses the level to which an individual experiences ruminative mood states with 22 items rated on a 4-point scale from 1 (almost never) to 4 (almost always). An example of an item is "generally, how often do you think about all your shortcomings, failings, faults, mistakes?" Rumination has been shown to be a mediator of the relationship between mindfulness and depressive symptoms ( $\alpha=.95$; Shahar, Britton, Sbarra, Figueredo, \& Bootzin, 2010).

Affect. Negative affect and positive affect were assessed by having participants indicate the extent to which they felt 20 moods (e.g., nervous, anxious, tense, joy) (Appendix K). Items from the PANAS (Studies 1 and 2), the PANAS X and from the anxiety subscales scales (Wegner, Broome, \& Blumberg, 1997) were chosen specifically 
related to correlates of mindfulness including anxiety and feelings of relaxation to validate in this sample how mindfulness was related to these constructs. The rating scale ranges from 0 (none of the time) to 4 (all of the time), over the course of the week, with 10 items each for positive affect and negative affect. Dispositional level NA $(\alpha=.91)$ and PA $(\alpha=.92)$ were calculated as the average score across of the 10 moods reported by a participant.

Daily

Activity check. In the AM assessment, immediately after completing the experiential exercise, on a separate screen, participants described the task they were assigned for the day (Appendix L). In the PM assessment, to assess compliance with the study procedures, participants were asked to describe the task they were assigned that day, and asked to "Please rate the amount to which you engaged this activity throughout the day", from 1 (did not complete activity) to 4 (engaged several times throughout the day).

Affect. As in the pre-test scales, daily positive and negative affect was assessed using 20 items from the PANAS and PANAS-X with instructions adapted to reflect the amount to which the individual experienced each of the emotions that day (Appendix M). Items were chosen to reflect both general positive or negative affect, as well as emotions conceptually specific to mindfulness including anxiety and feelings of relaxation to validate in this sample how mindfulness was related to these constructs. The rating scale ranged from 0 (none of the time) to 4 (all of the time), with 10 items for each Positive Affect and Negative Affect. Daily NA and PA scores were each calculated as the average 
score across of the 10 moods reported by a participant each day and positive affect (average daily $\alpha=.92)$ and negative affect $(\alpha=.92)$.

Perceived stress. Participants reported their most stressful event of the day and were asked to rate how stressful or traumatic the event was from 1 (not at all) to 7 (very stressful) (Appendix N). Participants also completed a single item of "how much stress did you experience today" from 1 (not at all) to 7 (very much). A mean score of the two items of how stressful the day's event was as well as how much stress they experienced that day was computed $(\alpha=.91)$.

Daily Purpose. Three items were adapted from the Meaning in Life scale (Steger, Frazier, Oishi, \& Kaler, 2006) and the Revised Youth Purpose Scale (Bundick et al., 2006), which were previously validated as a daily measure of purpose in emerging adults (Burrow \& Hill, 2013). Items include "My life has a clear sense of purpose", "I have discovered a satisfying life purpose" and "my life has no clear purpose." Items are rated on 7-point scale from 1 (absolutely untrue) to 7 (absolutely true) (Appendix O). The Cronbach's alpha in that previous study was .85 (Burrow \& Hill, 2013). The average Cronbach's alpha for the current study was .92 .

Daily Activities. Participants completed an inventory of 20 daily activities they engaged in each day from the categories of purposeful activities related to occupational, creative or pro-social aims, mindful activities and other activities (Appendix P). Participants indicated whether they engaged in the activity or not that day, and if so indicated the number of minutes spent engaging in the activity that day. Daily purpose activities were derived from common orientations to purpose previously identified in college students, such as pro-social activities (e.g. "Did you volunteer your time?"), 
financial activities ("Did you do something today to benefit your financial future") and creative activities ("Did you create artistic work") (Hill et al., 2010). Four items were included to measure mindful activities (yoga, meditation, mindful walking and carefully listening), as well as four items of day-to-day activities (checking social media and watching television).

Post-intervention follow-up

Participants completed the same purpose $(\alpha=.87)$, mindfulness, $(\alpha=.89)$, life satisfaction $(\alpha=.90)$, perceived stress $(\alpha=.90)$, rumination $(\alpha=.96)$, negative affect $(\alpha=$ $.92)$ and positive affect $(\alpha=.94)$ scales as in the pre-test questionnaires.

Data cleaning. Of the 87 participants recruited who completed the baseline survey, 65 completed the next day of daily surveys. Only participants that completed at least two days of either intervention were kept in the final analyses for the daily surveys. Six participants were removed because they only completed the baseline and one day of the intervention and five participants were removed because they had completed the survey more than once or answered the surveys with suspicious patterns of response (answered with the same number across all scales). Despite some of the variables not being normally distributed, HLM analyses are robust to violations of normality so data was not transformed. One participant scored 3.63 SD below the mean for purpose at posttest, so their score was brought to within 2.50 SD of the mean when their score was removed.

\section{Correlations}

\section{Results}

Bivariate Associations. For descriptive purposes, bivariate associations were performed among study variables at pre- and post-test within each group (See Table 6 
and Table 7). Associations among pre-test variables are below the diagonal, and correlations between post-test variables are along the top diagonal. The relationships between major study variables replicated the findings from Studies 1 and 2 both with respect to the directionality and general magnitude of relationships between variables such as mindfulness and purpose (correlations between .46 to .55 from Studies 1 and 2 and $r=.38$ in the control group and .50 at pre-test). The strength of these associations was higher at post-test for both groups (mindfulness $r=.64$, control $r=.49$, all $p<.05$ ).

Test of randomization. Dispositional levels of mindfulness and purpose were compared between groups at pre-test to determine if there are any between group differences. As expected, pre-test variable scores were not significant between groups for mindfulness $(t(60)=.17, p>.05)$ or purpose $(t(60)=-.98, p>.05)$.

Intervention test. To determine if the intervention had an effect, the pre/post measures of mindfulness were compared. To test the expectation that mindfulness would increase more in the intervention group than the control group, a repeated measures ANOVA with group as a moderator was tested (Table 8), with mindfulness measured at pre and post intervention (See Table 5 for study predictions). To control for the potential week effects of the school semester and exams, week was included as a covariate for the analyses. There were no significant effects for group, time, or an interaction of group and time. Dosage effects were to be examined, however most (54 of the 65) participants completed at least 4 days of the intervention. Therefore, there was not enough variability to test whether effects were stronger with greater intervention participation.

Group Tests. ANOVAs were performed to examine changes from pre to post-test across the two groups on mindfulness, purpose, positive affect, negative affect, stress, life 
satisfaction and rumination (See Table 8). To examine the impact of the intervention on purpose, repeated measures ANOVAs were performed from pre to post-test to determine whether group moderates the change, with week of the study as a covariate, and test whether changes in purpose were higher in the intervention group. There were neither significant differences within groups from pre-test to post-test, nor were there significant differences in changes between the intervention and control group on any of the major study variables.

\section{Mediational tests of intervention for pre-and post- test measures}

To test the indirect effects of both group and dispositional mindfulness on change in purpose from pre-test to post-test, a bootstrapping approach with 5000 resamples was used (a detailed description of the technique was described in Studies 1 and 2). Results of the bootstrapping tests demonstrated that none of the proposed mediators were significant in explaining the relationship between group and change in purpose (See Table 9 and Figure 4). Positive affect, negative affect and stress were not significant mediators of the direct effect of group (mindfulness or control) on change in purpose when controlling for age, gender, school and week of completion. When conducting the same mediation tests with dispositional mindfulness as a predictor, none of the mediation effects were significant (See Table 10 and Figure 5). These results further support the ANOVA analyses in suggesting no significant difference from pre-test to post test on any major study variables.

\section{Testing three mediational pathways for daily measures}

Given that the daily data is organized hierarchically (daily observations within participant), tests of meditational pathways were a ssessed using Hierarchical Linear 
Modeling (HLM) version 6.34g (Raudenbush, Bryk \& Congdon, 2008). A benefit to using HLM to analyze repeated measures data is the ability to simultaneously model within-and between-person effects. Daily-level equations were estimated associations between daily feeling of purpose, activities, mood and perceived stress ${ }^{1}$.

Daily purpose was estimated from the mean of daily assessments of purpose:

$$
\text { Daily Purpose }=\beta_{0 j}+r_{i j}
$$

Where $\beta_{0 \mathrm{j}}$ is the average of daily ratings of purpose across the week for each person ${ }_{j}$, and $\mathrm{r}_{\mathrm{ij}}$ is the estimated error for each person ${ }_{\mathrm{j}}$, each day ${ }_{\mathrm{i}}$.

$$
\beta_{0 \mathrm{j}}=\gamma_{00}+\mu_{0 \mathrm{j}}
$$

Where $\gamma_{00}$ is the overall mean of purpose and $\mu_{0 \mathrm{j}}$ is the between-persons error term.

\section{Path 1}

The following daily-level equation was estimated to test whether daily purpose is influenced by increased daily positive emotions. This equation predicts the individual's average daily purpose based on their daily positive affect and pre-test levels of purpose.

$$
\text { Daily Purpose } \mathrm{ij}_{\mathrm{ij}}=\beta_{0 \mathrm{j}}+\beta_{1} \text { Respondent Day }+\beta_{2} \mathrm{PA}+\mathrm{r}_{\mathrm{ij}}
$$

Where purpose $\beta_{0 \mathrm{j}}=\gamma_{00}+\gamma_{01}$ School $+\gamma_{02}$ Week $+\gamma_{03}$ Condition $+\gamma_{04}$ Gender $+\gamma_{05}$ Purpose $1+\gamma_{06}$ Age $+\mu_{0 \mathrm{j}}$

$\beta_{0 \mathrm{j}}$, the intercept, is their predicted average purpose; $\beta_{1}$ is a partial regression slope representing the effect of positive affect and $\beta_{2}$ is the day of the week.

As predicted the daily affirmation intervention was a stronger predictor of daily positive affect than the mindfulness intervention, such that those in the positive

\footnotetext{
${ }^{1}$ Additional analyses were run to examine whether the effects of the daily variables (Positive Affect, Negative Affect and Stress) on purpose interacted with group membership, but these were excluded from here as the effects were not significant.
} 
affirmation group reported greater daily positive affect than those that received the mindfulness intervention $(b=.34, S E=.15, p<.05)$. It was hypothesized that the mindfulness intervention and fluctuations in positive affect would be associated with increases in purpose. Estimates resulting from the HLM analysis for this pathway are presented in Table 11. In support of the hypothesis, fluctuations in daily purpose were systematically associated with fluctuations in participants' positive mood.

Previous research and Studies 1 and 2 demonstrate that positive affect is related to greater reports of purpose, so it was tested whether mindfulness influenced daily levels of purpose above and beyond the effects of positive affect. Participants in the mindfulness condition reported greater daily purpose than those in the positive affirmation condition $(\gamma(03), b=.33, S E=.15, p<.05)$ when controlling for the effects of positive affect and school, gender and age. This result replicates and extends both Study 1 and 2 results by providing evidence that positive affect plays a role in one's daily feelings of purpose, that positive affirmation intervention may be effective at increasing positive affect, and that experiencing greater positive affect led one to report a greater sense of purpose that day. These findings extend from Studies 1 and 2 in that mindfulness has an impact on daily levels of purpose that is unique from positive affect.

\section{Path 2}

The following daily-level equation was estimated to test whether daily levels of purpose were influenced by daily negative affect and perceived stress. This equation predicts the individual's average change in purpose based on their daily negative affect, daily-perceived stress, and pre-test levels of purpose.

Daily Purpose $e_{i j}=\beta_{0 j}+\beta_{1}$ Respondent Day $+\beta_{2} \mathrm{NA}+\beta_{2}$ Stress $+\mathrm{r}_{\mathrm{ij}}$ 
Where purpose $\beta_{0 \mathrm{j}}=\gamma_{00}+\gamma_{01}$ Condition $+\gamma_{02}$ Gender $+\gamma_{03}$ Age $+\gamma_{04}$ School $+\gamma_{05}$ Week + $\gamma_{06}$ Purpose $1+\mu_{0 j}$

Contrary to predictions, participants in the positive affirmation condition showed a trend of reporting less stress $(\gamma(03), b=-.53, S E=.17, p<.10)$ and less negative affect $(\gamma(03), b=-.23, S E=.13, p<.10)$ than the mindfulness group when the equations were run separately. Given this, it was tested whether mindfulness influenced daily levels of purpose above and beyond the effects of stress and negative affect (see Table 11). Indeed, participants in the mindfulness group $(b=-.49 S E=.17, p<.10)$ reported greater daily purpose than those in the positive affirmation group, and this effect was above and beyond the effects of daily stress, and daily negative affect. This result replicates and extends both Study 1 and 2 results by providing evidence that lower levels of stress contribute to one's sense that they felt purposeful that day and mindfulness predicts daily purpose commitment uniquely from the effects of stress and negative affect.

\section{Path 3}

The following daily-level equation was estimated to test whether daily purpose was predicted by through engagement in daily purpose-relevant activities. This equation predicts the individual's average change in purpose commitment based on their engagement with daily activities.

$$
\text { Daily Purpose }{ }_{i j}=\beta_{0 j}+\beta_{1 j} \text { Respondent Day }+\beta_{2 j} \text { Daily Activities }+r_{i j}
$$

Where purpose $\beta_{0 \mathrm{j}}=\gamma_{00}+\gamma_{01}$ Condition $+\gamma_{02}$ Gender $+\gamma_{03}$ Age $+\gamma_{04}$ School $+\gamma_{05}$ Week + $\gamma_{06}$ Purpose $1+\mu_{0 j}$

As displayed in Table 13, the evidence for third pathway was supported in that the sum of the daily activities engaged in significantly predicted one's daily purpose commitment 
$(\gamma(30), b=.01, S E=.01, p<05)$. Furthermore, the mindfulness group predicted daily fluctuations in purpose beyond that of daily activities $(b=-.37, S E=.17, p<.05)$. This result is a unique contribution and extends the previous studies in that engaging in activities that are considered potentially meaningful and related to achieving one's goals are related to feelings of purposefulness.

\section{Intermediate Summary}

The aim of Study 3 was to examine the effects of daily positive affect, negative affect, stress and daily activities on daily feelings of purpose. The goal of the mindfulness intervention was to determine whether increasing mindfulness influences purpose on a daily or trait level, also to determine if the proposed pathways of positive affect, negative affect and stress, and daily activities are potential ways to intervene and promote purpose. The effects of the study provide preliminary answers to the research questions proposed previously.

Study 3 did not provide evidence that the brief, online intervention of daily mindfulness skills has a measurable effect on dispositional levels of mindfulness from pre-test to post-test. Participants in the intervention condition did not report greater levels of dispositional mindfulness from pre-test to post test. One potential explanation for this finding is that the intervention implementation may have been too brief to enact influence on trait level mindfulness. Previous two-week long online interventions of mindfulness have shown positive effects on trait levels of mindfulness (Cavanagh et al., 2013), suggesting the potential need to double the length of the current intervention.

Alternatively, the use of mindful skills without formal mindfulness meditation may simply not be effective for enacting change on trait levels of mindfulness. 
In regards to the proposed mechanisms in which purpose may be influenced by mindfulness, daily feelings of purpose were related to greater positive affectivity, greater purpose-relevant activity engagement, and lower levels of daily stress. However, the mindfulness intervention did not influence these outcomes more than the positive affirmation control group. Traditionally, mindfulness interventions encourage feeling both positive and negative emotions and sensations as they are, so individuals in the mindful condition may have an increased awareness of negative emotions and stress, which in turn could be adaptive for purpose development as discussed later. Instead, the affirmation control may prove better at influencing daily levels of affect and stress.

Study 3 provided important information regarding what purposeful people do on a daily basis. Dispositional levels of purpose were related to greater overall engagement in activities that may be more meaningful and related to one's purpose. Although at the trait level there was no mean level change in purpose or mindfulness over the course of the week, participants in the mindfulness condition were more likely to report a greater sense of purpose on a daily basis than the control condition, a focus of the general discussion below. 
Figure 3. Consort diagram demonstrating Study 3 procedure.

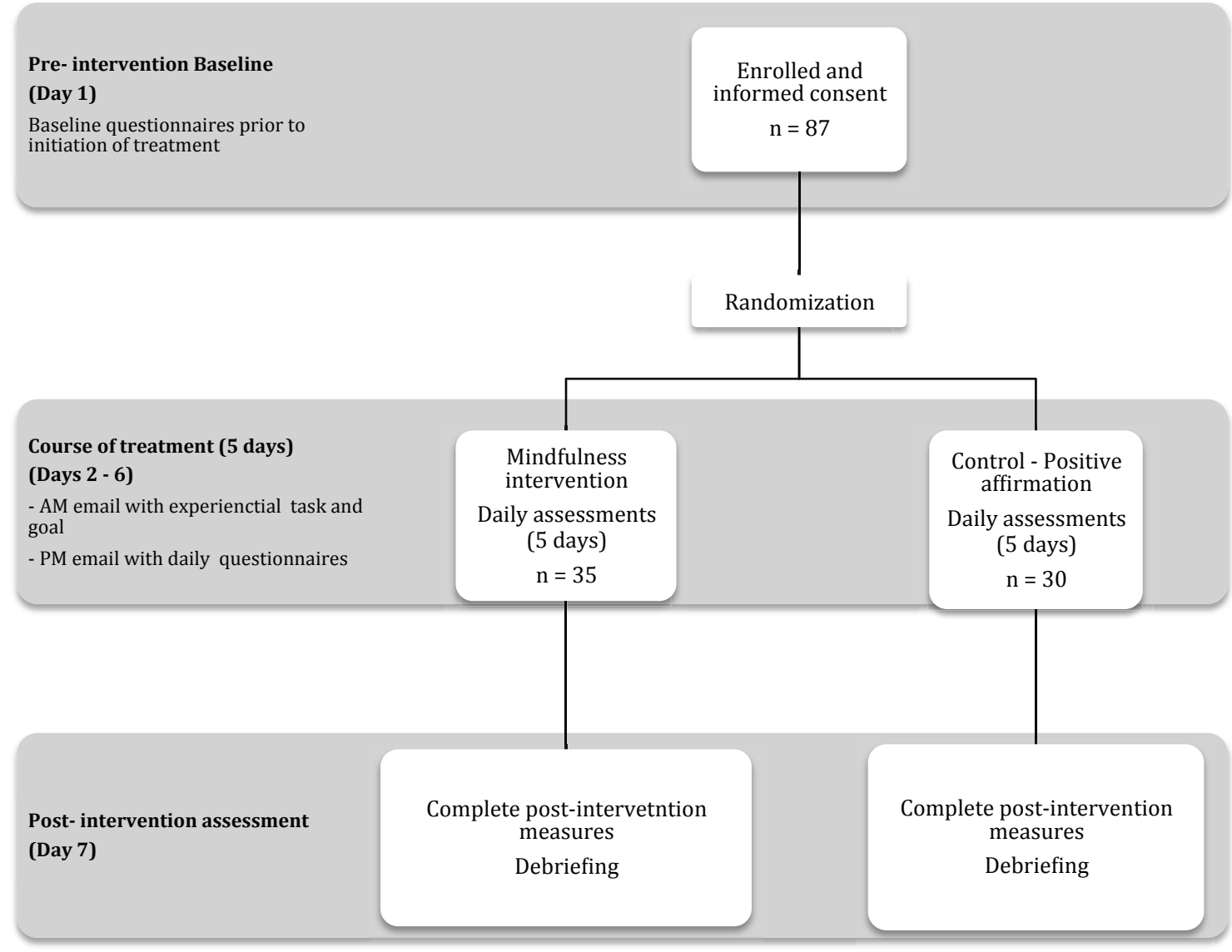


Table 5: Predicted results from pre- and post-test on major outcome variables in Study 3

\begin{tabular}{|c|c|c|c|}
\hline \multirow[t]{2}{*}{ Outcome } & \multicolumn{3}{|c|}{ Changes from Pre to Post-Test } \\
\hline & Intervention & $\begin{array}{l}\text { Magnitude of } \\
\text { change }\end{array}$ & Control \\
\hline Mindfulness & Higher & $>$ & No difference \\
\hline Purpose & Higher & $>$ & Higher \\
\hline Rumination & Lower & $>$ & No difference \\
\hline Resilience & Higher & $>$ & Higher \\
\hline Stress & Lower & $>$ & Lower \\
\hline $\begin{array}{c}\text { Life } \\
\text { Satisfaction }\end{array}$ & Higher & $>$ & Higher \\
\hline $\begin{array}{c}\text { Negative } \\
\text { Affect }\end{array}$ & Lower & $>$ & Lower \\
\hline Positive Affect & Higher & $<$ & Higher \\
\hline
\end{tabular}


Table 6: Study 3 correlations between mindfulness, purpose and affect at pre-and post-test for mindfulness condition

\begin{tabular}{|c|c|c|c|c|c|c|c|}
\hline & $\begin{array}{c}\text { Mindfulness } \\
2\end{array}$ & $\begin{array}{c}\text { Purpose } \\
2\end{array}$ & $\begin{array}{c}\text { PA } \\
2\end{array}$ & $\begin{array}{c}\text { NA } \\
2\end{array}$ & $\begin{array}{c}\text { Stress } \\
2\end{array}$ & $\begin{array}{c}\text { Life } \\
\text { Satisfaction } \\
2 \\
\end{array}$ & $\begin{array}{c}\text { Rumination } \\
2\end{array}$ \\
\hline Mindfulness 1 & - & $.64 *$ & $.53 *$ & $-.55^{*}$ & $-.49 *$ & .23 & $-.60 *$ \\
\hline Purpose 1 & $.50^{*}$ & - & $.48^{*}$ & $-.54 *$ & $-.46^{*}$ & $.57 *$ & -.68 \\
\hline PA 1 & $.58^{*}$ & $.58 *$ & - & -.17 & -.35 & .21 & $-.39 *$ \\
\hline NA 1 & $-.62 *$ & $-.35 *$ & -.21 & - & $.62 *$ & -.29 & $.67 *$ \\
\hline Stress 1 & $-.54 *$ & -.33 & $-.39 *$ & $.62 *$ & - & -.31 & $.73^{*}$ \\
\hline Life Satisfaction 1 & $.38^{*}$ & $.46^{*}$ & $.40^{*}$ & $-.43 *$ & $-.47 *$ & - & -.37 \\
\hline Rumination 1 & $-.60 *$ & $-.46^{*}$ & $-.39 *$ & $.65^{*}$ & $.81 * *$ & $-.40 *$ & - \\
\hline
\end{tabular}


Table 7: Study 3 correlations between mindfulness, purpose and affect at pre-and post-test for positive affect condition

\begin{tabular}{|c|c|c|c|c|c|c|c|}
\hline & $\begin{array}{l}\text { Mindfulness } \\
2\end{array}$ & $\begin{array}{l}\text { Purpose } \\
2\end{array}$ & $\begin{array}{c}\mathrm{PA} \\
2\end{array}$ & $\begin{array}{c}\text { NA } \\
2\end{array}$ & $\begin{array}{c}\text { Stress } \\
2\end{array}$ & $\begin{array}{c}\text { Life } \\
\text { Satisfaction } \\
2\end{array}$ & $\begin{array}{c}\text { Rumination } \\
2\end{array}$ \\
\hline Mindfulness 1 & - & $.49 *$ & $.57 *$ & $-.52 *$ & $-.51 *$ & $.48^{*}$ & $-.63 *$ \\
\hline Purpose 1 & $.38^{*}$ & - & .27 & $-.60 *$ & $-.50 *$ & $.67 *$ & $-.56^{*}$ \\
\hline PA 1 & $.47 *$ & $.59 *$ & - & -.17 & $-.51 *$ & $.55^{*}$ & $-.33 *$ \\
\hline NA 1 & $-.56^{*}$ & $-.55^{*}$ & -.09 & - & $.57 *$ & $-.60 *$ & $.80^{*}$ \\
\hline Stress 1 & $-.49 *$ & $-.49 *$ & $-.51 *$ & $.45^{*}$ & - & -.72 & $.73^{*}$ \\
\hline Life Satisfaction 1 & $.24 *$ & $.54^{*}$ & $.40 *$ & $-.41 *$ & $-.52 *$ & - & $-.54 *$ \\
\hline Rumination 1 & $-.63 *$ & $-.48 *$ & -.18 & $.79^{*}$ & $.56^{*}$ & $-.45^{*}$ & - \\
\hline
\end{tabular}


Table 8: Study 3 differences between groups from pre- to post-test on major outcome variables with week as a covariate in the ANOVAs.

\begin{tabular}{|c|c|c|c|c|c|c|c|}
\hline \multirow[t]{2}{*}{ Outcome } & \multicolumn{2}{|c|}{ Control } & \multicolumn{2}{|c|}{ Mindfulness } & \multirow[t]{2}{*}{ Group F } & \multirow[t]{2}{*}{ Time F } & \multirow[t]{2}{*}{ Interaction $\mathbf{F}$} \\
\hline & $\begin{array}{c}\text { Pre } \\
\text { M (SD) }\end{array}$ & $\begin{array}{c}\text { Post } \\
\text { M (SD) }\end{array}$ & $\begin{array}{c}\text { Pre } \\
\text { M (SD) }\end{array}$ & $\begin{array}{c}\text { Post } \\
\text { M (SD) }\end{array}$ & & & \\
\hline Mindfulness & $\begin{array}{l}3.26 \\
(.57)\end{array}$ & $\begin{array}{l}3.26 \\
(.61)\end{array}$ & $\begin{array}{l}3.27 \\
(.47)\end{array}$ & $\begin{array}{l}3.19 \\
(.46)\end{array}$ & .04 & .35 & .01 \\
\hline Purpose & $\begin{array}{l}3.82 \\
(.92)\end{array}$ & $\begin{array}{l}3.80 \\
(.92)\end{array}$ & $\begin{array}{l}3.67 \\
(.62)\end{array}$ & $\begin{array}{l}3.71 \\
(.67)\end{array}$ & .04 & .04 & .09 \\
\hline Positive Affect & $\begin{array}{l}3.31 \\
(.89)\end{array}$ & $\begin{array}{c}3.17 \\
(1.02)\end{array}$ & $\begin{array}{l}3.42 \\
(.76)\end{array}$ & $\begin{array}{l}3.06 \\
(.71)\end{array}$ & .00 & 2.98 & .35 \\
\hline Negative Affect & $\begin{array}{c}2.41 \\
(1.00)\end{array}$ & $\begin{array}{c}2.19 \\
(1.01)\end{array}$ & $\begin{array}{l}2.31 \\
(.82)\end{array}$ & $\begin{array}{l}2.15 \\
(.76)\end{array}$ & .10 & 3.34 & .71 \\
\hline Stress & $\begin{array}{l}2.96 \\
(.84)\end{array}$ & $\begin{array}{l}2.81 \\
(.86)\end{array}$ & $\begin{array}{l}2.93 \\
(.73)\end{array}$ & $\begin{array}{l}2.94 \\
(.67)\end{array}$ & .07 & 2.76 & .86 \\
\hline Life Satisfaction & $\begin{array}{l}23.48 \\
(8.64)\end{array}$ & $\begin{array}{l}23.85 \\
(8.47)\end{array}$ & $\begin{array}{l}21.53 \\
(6.28)\end{array}$ & $\begin{array}{l}20.77 \\
(6.67)\end{array}$ & 1.69 & .42 & 1.01 \\
\hline Rumination & $\begin{array}{c}49.93 \\
(16.06)\end{array}$ & $\begin{array}{c}49.03 \\
(16.80)\end{array}$ & $\begin{array}{c}51.13 \\
(15.32)\end{array}$ & $\begin{array}{c}47.90 \\
(15.18)\end{array}$ & .00 & .01 & .56 \\
\hline
\end{tabular}

Note. ${ }^{*} p<.05$ 
Figure 4. Study 3 mediation model for group predicting change in purpose controlling for age, gender, school and week.

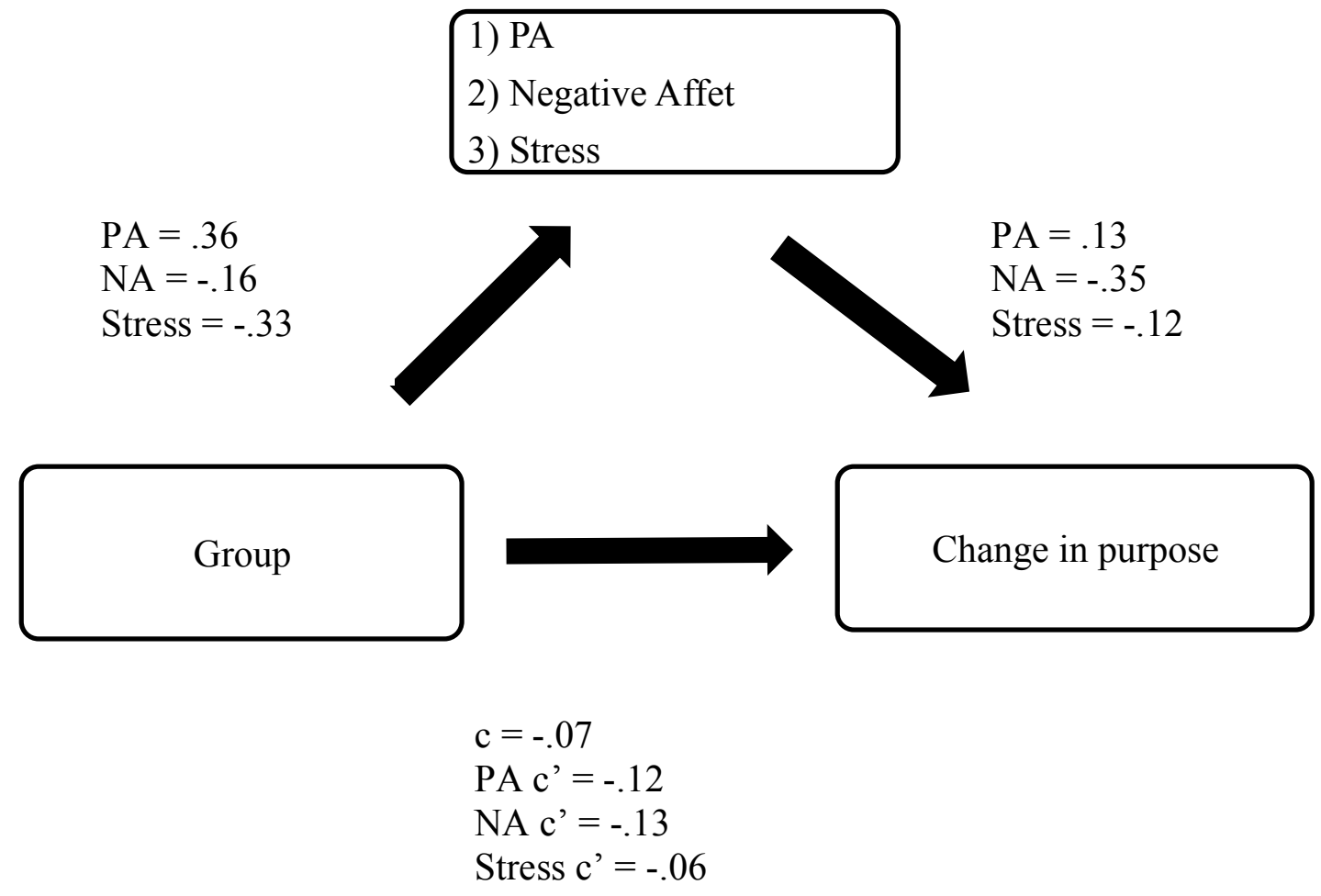

Note. Analyses were run separately for each mediator. 
Figure 5. Study 3 mediation model for baseline mindfulness predicting change in purpose controlling for age, gender, school and week.

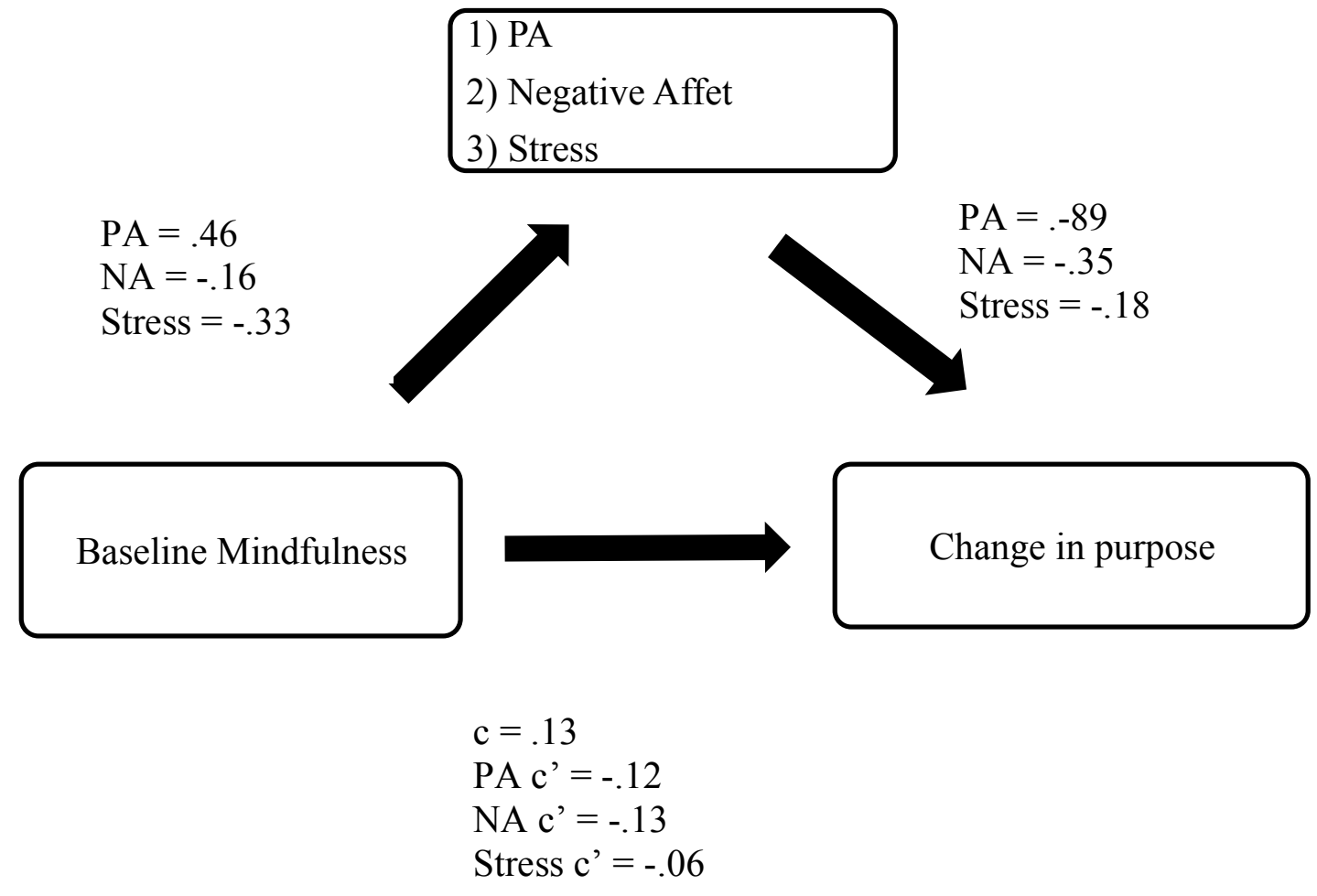

Note. Analyses were run separately for each mediator. 
Table 9: Testing mediator effects of positive affect, negative affect and stress using bootstrapping with group as predictor controlling for age, gender, school and week in Study 3.

\begin{tabular}{|c|c|c|c|c|}
\hline \multirow[t]{2}{*}{ Mediator } & \multicolumn{2}{|c|}{$\begin{array}{c}\text { Indirect Effect } \\
95 \% \mathrm{CI}\end{array}$} & \multirow[t]{2}{*}{$\begin{array}{l}\text { Direct Effect (c) of group } \\
\text { on purpose }\end{array}$} & \multirow[t]{2}{*}{$\begin{array}{l}\text { Direct Effect (c') } \\
\text { controlling for mediator } \\
\text { t-test }\end{array}$} \\
\hline & LL & UL & & \\
\hline & & & -.072 & \\
\hline Positive Affect & -.019 & .135 & & -.118 \\
\hline Negative Affect & -.041 & .181 & & -.127 \\
\hline Stress & -.056 & .134 & & -.017 \\
\hline
\end{tabular}

Note. ${ }^{*} p<.05$. 
Table 10: Testing mediator effects of positive affect, negative affect and stress using bootstrapping with baseline mindfulness as predictor controlling for age, gender, school and week in Study 3.

\begin{tabular}{|c|c|c|c|c|}
\hline \multirow[t]{2}{*}{ Mediator } & \multicolumn{2}{|c|}{$\begin{array}{c}\text { Indirect Effect } \\
99 \% \text { CI }\end{array}$} & \multirow[t]{2}{*}{$\begin{array}{c}\text { Direct Effect (c) of } \\
\text { baseline mindfulness on } \\
\text { purpose }\end{array}$} & \multirow[t]{2}{*}{$\begin{array}{l}\text { Direct Effect (c') } \\
\text { controlling for mediator } \\
\text { t-test }\end{array}$} \\
\hline & LL & UL & & \\
\hline & & & .132 & \\
\hline Positive Affect & -.046 & .131 & & .067 \\
\hline Negative Affect & -.005 & .178 & & .066 \\
\hline Stress & -.043 & .148 & & .092 \\
\hline
\end{tabular}

Note. $* p<.05$. 
Table 11: Model estimates for predicting daily purpose from positive affect ("Path 1") in Study 3.

\begin{tabular}{lccc}
\hline Effect & Coefficient & SE & $t$ \\
\hline Average purpose, $\beta_{0}$ & 3.51 & .74 & $4.77^{*}$ \\
Intercept, $\gamma_{00}$ & -.09 & .21 & -.41 \\
School, $\gamma_{01}$ & .27 & .09 & $3.00^{*}$ \\
Week $\gamma_{02}$ & -.53 & .17 & $-3.09^{*}$ \\
Group, $\gamma_{03}$ & .07 & .03 & 2.49 \\
Age, $\gamma_{04}$ & -.69 & .18 & $-3.94^{*}$ \\
Gender, $\gamma_{05}$ & 1.24 & .11 & $11.55^{*}$ \\
Baseline Purpose, $\gamma_{06}$ & & & \\
Weekday, $\beta_{1}$ & .04 & .06 & .61 \\
Intercept, $\gamma_{10}$ & & &
\end{tabular}

Note. Group indicates condition that participants were assigned $1=$ Mindfulness intervention, $2=$ Positive affirmation control. The variables were coded as following Schools were coded as 1 = Carleton University, $2=$ Algonquin College; Female =2, Male $=1$. Intercept values reflect the effect on daily purpose for the variable of interest. ${ }^{*} \mathrm{p}<.05, \mathrm{n}=60$. 
Table 12: Model estimates for predicting daily purpose, negative affect and stress ("Path 2") in Study 3.

\begin{tabular}{|c|c|c|c|}
\hline Effect & Coefficient & $\mathrm{SE}$ & $t$ \\
\hline \multicolumn{4}{|c|}{ Average purpose, $\beta_{0}$} \\
\hline Intercept, $\gamma_{00}$ & 5.35 & .71 & $7.56^{*}$ \\
\hline School, $\gamma_{01}$ & -.10 & .21 & -.45 \\
\hline Week $\gamma_{02}$ & .31 & .09 & $3.50 *$ \\
\hline Group, $\gamma_{03}$ & -.49 & .17 & $-2.82^{*}$ \\
\hline Age, $\gamma_{04}$ & .07 & .03 & 2.48 \\
\hline Gender, $\gamma_{05}$ & -.74 & .18 & $-4.19 *$ \\
\hline Purpose, $\gamma_{06}$ & 1.33 & .11 & $12.25 *$ \\
\hline \multicolumn{4}{|l|}{ Weekday, $\beta_{1}$} \\
\hline Intercept, $\gamma_{20}$ & .02 & .06 & .26 \\
\hline \multicolumn{4}{|c|}{ Negative Affect, $\beta_{2}$} \\
\hline Intercept, $\gamma_{30}$ & -.08 & .16 & -.48 \\
\hline \multicolumn{4}{|l|}{ Stress, $\beta_{3}$} \\
\hline Intercept, $\gamma_{40}$ & -.14 & .06 & $-2.28 *$ \\
\hline
\end{tabular}


Table 13: Model estimates for predicting daily purpose from daily activity engagement ("Path 3”) in Study 3.

\begin{tabular}{lccc}
\hline Effect & Coefficient & SE & $t$ \\
\hline $\begin{array}{l}\text { Average purpose, } \beta_{0} \\
\text { Intercept, } \gamma_{00}\end{array}$ & 4.82 & .68 & $7.12^{*}$ \\
School, $\gamma_{01}$ & -.02 & .21 & -.10 \\
Week $\gamma_{02}$ & .28 & .09 & $3.09^{*}$ \\
Group, $\gamma_{03}$ & -.38 & .17 & $-2.24^{*}$ \\
Age, $\gamma_{04}$ & .05 & .03 & 1.80 \\
Gender, $\gamma_{05}$ & -.87 & .17 & $-5.05^{*}$ \\
Purpose, $\gamma_{06}$ & 1.34 & .11 & $12.56^{*}$ \\
Weekday, $\beta_{1}$ & & & .06 \\
Intercept, $\gamma_{20}$ & .03 & .01 & $3.69^{*}$ \\
Daily Activities, $\beta_{2}$ & & .01 &
\end{tabular}

Note. Group indicates condition that participants were assigned $1=$ Mindfulness intervention, $2=$ Positive affirmation control. The variables were coded as following Schools were coded as $1=$ Carleton University, $2=$ Algonquin College; Female $=2$, Male $=1$. Intercept values reflect the effect on daily purpose for the variable of interest. ${ }^{*} \mathrm{p}<.05, \mathrm{n}=60$. 


\section{Chapter 8: General Discussion}

Purpose has been repeatedly linked to emotional health (Burrow \& Hill, 2011), less negative mood after a stressor (Smith \& Zautra, 2004) and greater reports of life satisfaction and happiness (Ulmer, Range, \& Smith, 1991; Zika \& Chamberlain, 2011). Furthermore, it appears possible to induce a sense of purpose momentarily (Burrow \& Hill, 2013), but it remains unclear how to best intervene on purpose. Building upon these findings, the three studies above replicate and extend this literature in several important ways. In the following paragraphs, I will address four such research questions advanced by this project.

Why is there a relationship between purpose and mindfulness?

Across three studies, there was mixed evidence to support three potential mechanisms through which mindfulness may influence one's sense of purpose. In the first two cross-sectional studies, both at the facet level and overall mindfulness were related to purpose in life, across multiple measures of the construct. Furthermore, despite the strong correlation, mindfulness and purpose independently predict well-being outcomes. When testing these potential mechanisms at the daily level, however, the mindfulness intervention had the same influence on these affect and stress variables as the active control condition. That said, mindfulness uniquely predicted daily purpose commitment above and beyond the effects of positive affect, negative affect, stress, and daily activity engagement. These findings provide evidence that mindfulness has a strong influence on daily purpose, but it may not be through the three proposed pathways.

The intervention study demonstrated the efficacy of both the mindfulness intervention and the positive affirmation intervention to influence daily purpose 
commitment. Moreover, these studies allowed tests of three potential mechanisms to influence daily levels of purpose. First, the intervention study provides support for broaden-and-build theory of emotions, that by experiencing positive emotions, the individual gains access to greater coping resources and they have an enhanced ability to flexibly respond to stressors (Fredrickson, 2001). In all three studies, greater positive affect was related to greater reports of purpose at both the cross-sectional level and at the daily level.

Secondly, building off the first two cross-sectional studies, mindfulness and purpose were both related to lower levels of negative affect and less reported stress in the intervention study on a daily level. However, negative affect was not a significant predictor of the amount to which one felt purposeful that day when controlling for the effect of stress. The relationships between these variables interact differently at a microlevel, so assessing what is occurring at the daily level may help to explain these findings. The mindfulness literature has provided some evidence that even if negative emotions are experienced, it is how they are perceived that influences stress, and in this case purpose (Greenberg \& Merian, 2013). Mindful individuals may actually be better at noticing and describing their emotions in general, and therefore may report experiencing greater negative moods that day because they were more attentive to their feelings. In other words, mindful individuals may not necessarily experience fewer negative emotions, but instead be better able to notice and pay attention to their negative emotions without letting them impact their daily activities or purpose commitment that day.

The intervention study demonstrated that the positive affirmation group and the mindfulness group did not differ on their daily levels of stress. Furthermore, the 
mindfulness intervention influenced daily reports of purpose beyond this reduction of stress. Indeed, mindfulness has been related to greater perceived control to utilize adaptive coping strategies to handle stressors (Wallace \& Shapiro, 2006).

Finally, mindfulness may encourage people to engage in activities more relevant to their values, which in turn leads individuals to report that their life has a sense of purpose. Mindfulness might promote value-relevant behaviours because it fosters objective evaluation of the current moment and an increased awareness of one's actions (Chambers, Lo \& Allen, 2008). Moreover, mindful individuals may be better able to regulate and control their behaviour to better achieve their goals (Semple, Lee, Rosa, \& Miller, 2010).

Given that mindfulness played a role in daily purpose above and beyond daily moods and stress, the question of how mindfulness might influence purpose is still unanswered. Whereas the daily affirmation intervention may influence purpose through increasing positive mood and decreasing stress and negative mood, mindfulness was playing a different role. One possibility is pathway 3 presented above which proposed that mindfulness may influence purpose by encouraging value-relevant activities. This pathway can be better tested in future research that collects baseline levels of activity engagement, using a more complex measure. However, this is not the full story as the intervention retained a significant effect on daily purpose, above and beyond activity engagement.

Another possibility then is that positive affirmations may influence feeling good about one's goals, and feeling as though life has purpose, mindfulness might be more related to actually providing a direction or aim to one's day. The mindfulness skills were 
theorized to increase self-awareness, being observant of one's surroundings and thoughts, paying attention to one's thoughts, feelings and self-talk. Mindfulness may promote daily levels of purpose through an ability to act with awareness, to articulate one's goals, to observe the environment and through an increased self-awareness and regulation of one's activities and values. Mindfulness may promote engagement and focus on things that are meaningful to one's life and enhance one's ability to pursue these activities. To determine whether mindfulness would enact these changes, there is a need to look at this at a more micro-level, that is to look at behaviours that are specific to one's specific idiosyncratic purpose (purpose orientations and purpose relevant behaviours). The current work provided preliminary evidence for the importance of looking at daily behaviours. The proposed pathway 3 described that through engagement in activities that allow individuals to reflect on their goals and values, they may feel a greater sense of purpose.

What is the potential for intervening on mindfulness as a mechanism for inducing purpose?

While there is a growing body of literature that purpose promotes several wellbeing outcomes and we can intervene on it (Bronk et al., 2010), there are few empirical demonstrations that we can enact long-term changes in purpose. Recent studies (Burrow \& Hill, 2013) demonstrate that you can induce a momentary sense of purpose by getting people to think or write about their goals and values. One value of the current series of studies is that it elucidated potential pathways by which researchers could envision reinforcing purpose in the short- and long-term. Moreover, given that positive affect, stress, activity engagement, and the intervention all held unique effects on purpose, it appears that researchers would benefit from adopting a multifaceted approach. 
For instance, the mindfulness intervention techniques from Study 3 could be used in tandem with other intervention methods, such as a goal-training program, to promote purpose (Sheldon, Kasser, Smith \& Share, 2002). Mindful skills interventions can be combined with existing interventions to go beyond simply helping people set goals, and actually help people maintain their engagement in daily activities to feel good about their goal pursuit. A combination of the two current groups as a daily affirmation and mindfulness intervention would be one possible way to intervene on purpose as the results suggest they are influencing different aspects of purpose in life. The findings of the current studies demonstrate that mindfulness is really central for intervening on purpose. Beyond the benefits of positive affirmations and feeling good, mindfulness may be addressing the prospective, directing parts of purpose as a self-organizing aim. Mindful skills training may help individuals direct actions towards behaviours that are relevant to one's values.

How do these results add to the literature on mindfulness interventions?

Study 3 provided evidence that this brief intervention of mindfulness skills did not produce measurable changes in trait levels of mindfulness over the course of the week, but did have an effect on feelings of purpose. This was one of the first studies to assess skills associated with mindfulness without formal mindfulness meditation. As such, this intervention has several potentially meaningful implications for intervening on mindfulness. First, participants in the weeklong online intervention showed great compliance and engagement in the daily activities without a clinician implementing or supervising the program. Second, the intervention influenced daily levels of purpose in life. As such, it provides evidence for the short-term efficacy for informal mindfulness 
techniques alone to produce meaningful effects. Mindfulness skills, independent of formal mindfulness training, might produce effects on a day-to-day level, but it is not known the role that these techniques play in enacting dispositional change. Past intervention research has focused on change in mindfulness six or twelve months later (Carmody \& Baer, 2009), but assessing the influence of the mindfulness skills on daily moods and activities may be another pathway by which people maintain compliance with the program. If the daily mindfulness activities lead to a greater sense of purposefulness, participants may be more likely to continue with the program if they can start to feel changes from the first days of the intervention.

\section{What implications do these results have for positive psychology?}

The current series of studies provides several important contributions to the field of positive psychology. First, these three studies provide evidence that purpose and mindfulness are empirically distinct constructs. In other words, there is not just one general "positivity" construct that captures all adaptive, positive psychology constructs. Second, there is a need to examine positive psychology constructs at the facet level rather than broadly, to better understand how to best develop and promote different outcomes. Third, it is important to move beyond testing positive psychology interventions against an inactive control, and instead start identifying how positive psychology interventions can influence well-being differentially. The current point is demonstrated in the positive affirmation control condition in which participants reported greater positive affect, but this condition did not influence daily purpose as effectively as mindfulness group.

Fourth, the series of studies demonstrated the need to examine both crosssectional and daily associations between variables. At the cross-sectional level, the 
influence of mindfulness on purpose appeared to be through a reduction in negative affect and stress, and increases in positive affect. However, at the daily level, mindfulness influenced daily purpose above and beyond the effects of moods and stress.

\section{Limitations and Future Directions}

That said, the current studies are not without their limitations that should be addressed in future research. First, the assessment of the intervention could be strengthened by employing more assessment occasions, in order to better assess changes over time. In particular, a follow-up two months after the initial assessment would provide insight as to whether the intervention had any lasting effects on well-being. Second, to better understand the trait level changes on the major study variables, the length of the intervention should be increased to determine if daily mindfulness skills can enact change on trait levels of mindfulness. Third, to further understand the significant week effect of the intervention, having all participants complete the interventions during the same timeframe would provide insight as to when such interventions should be best conducted.

In addition, the current study allows several important areas of future investigation with the current dataset but is beyond the scope of the current project. A few potential areas for exploration are described below. First, it is possible that the intervention could be more effective for different personalities; accordingly, the role of personality factors will be explored using data collected here. Second, qualitative analyses can better examine the hypotheses that mindfulness may be beneficial for promoting self-inquiry and articulation of goals. The intervention study collected qualitative data on the daily level describing positive moods and mindful experiences, as 
well as descriptions of goals and steps to achieve their goals from pre-test to post-test. Future work will analyze whether individuals in the mindfulness group were able to better articulate their goals than those in the positive mood group. Third, in regards to daily activities related to one's purpose, it is yet to be explored whether one's selfnominated purpose orientation (classified as creative, occupational or pro-social) predicts engagement in more activities related to their purpose over the course of the week. Fourth, future analyses can assess the lagged effect of positive mood, activity engagement and reduced stress one's sense of purpose and the cumulative effect that the intervention may be having. For instance, does the previous day's activity level influence one's sense of purpose today? This analysis will answer the question as to whether people are gaining or improving over the course of the week, and has the potential to be related to long-term changes over time. Finally, there are a number of potential moderators of the effects to evaluate in the future including pre-intervention practice of yoga or meditation experience. Both practice of yoga and previous meditation experience can influence dispositional mindfulness and the potentially the impact of the intervention (Baer et al., 2008). Further, both meditation and yoga are elements in clinically based programs used to promote mindfulness (Kabat-Zinn, 2003).

\section{Conclusions}

The current series of studies provided many important implications for both theoretical and applied conclusions. An important advancement is the assessment of daily purpose commitment as a function of one's daily activities. For instance, the positive relation between activity engagement and purpose commitment provides support for the notion of purpose is related to a greater agency towards activity engagement. This has 
important implications for interventions and fostering purpose through daily tasks that are aligned with one's goals and values. Having people identify and engage in activities that are related to their goals may lead them to a greater sense of purpose (Hill, Sumner, \& Burrow, 2014). Specifically, engagement in valued activities may increase the number of opportunities for exploring one's purpose.

Across the three current studies, not only was mindfulness related to purpose at the cross-sectional level, intervening upon mindfulness with informal mindfulness skills enacted influence on purpose above and beyond the effects of daily moods, activities and stress. These findings advance understating of purpose in life as a multifaceted construct that involves both affective and goal-directed components, and also how to help people live with more purpose on a daily basis. Future exploration of mindfulness as both a trait and a set of daily skills is warranted as a potential intervention help individuals live happier, more purposeful lives. 


\section{References}

Aarts, H., Custers, R. \& Holland, R. (2007). The nonconscious cessation of goal pursuit: When goals and negative affect are coactivated. Journal of Personality and Social Psychology, 92(2), 165-178.

Baer, R., Smith, G. \& Allen, K. (2004). Assessment of mindfulness by self-report: the Kentucky inventory of mindfulness skills. Assessment, 11(3), 191-206.

Baer, R., Smith, G., Hopkins, J., Krietemeyer, J \& Toney, L. (2006). Using self-report assessment methods to explore facets of mindfulness. Assessment, 13(1), 27-45.

Baer, R., Smith, G., Lykins, E., Button, D., Krietmeyer, J., Sauer, S., Walsh, E., Duggan, D. \& Williams, J. (2008). Construct validity of the Five Facet Mindfulness Questionnaire in meditating and non meditating samples. Assessment, 15(3), $329-342$

Baumeister, R. (1992). Meanings of life. New York: Guilford.

Bergogi, C., Tschacher, W. \& Kupper, Z. (2013). Measuring mindfulness: First steps towards the development of a comprehensive mindfulness scale. Mindfulness, 4 , $18-32$

Bishop, S., Lau, M., Shapiro, S., Carlson, L., Anderson, N., Carmody, J., Segal, Z., Abbey, S., Speca, M., Velting, D. \& Devins, G. (2004). Mindfulness: A proposed operational definition. Clinical Psychology: Science and Practice, 11(3), 230-241.

Bohlmeijer, E., ten Klooster, P. M., Fledderus, M. Veehof, M. \& Baer, R. (2011). Psychometric properties of the Five Facet Mindfulness Questionnaire in depressed adults and development of a short form. Assessment, 18, 308-320. 
Boyle, P., Barnes, L., Buchman, A. \& Bennett, D. (2009). Purpose in life is associated with mortality among community-dwelling older persons. Psychosomatic Medicine, 71, 574-579.

Bronk, K., Hill, P., Lapsley, D., Talib, T. \& Finch, H. (2009). Purpose, hope and life satisfaction in three age groups. The Journal of Positive Psychology. 4(6). 500510.

Bronk, K., Finch, H. \& Talib, T. (2010). Purpose in life among high ability adolescents. High Ability Studies, 21(2), 133-145.

Brown, K. \& Ryan, R. (2003). The benefits of being present: Mindfulness and its role in psychological well-being. Journal of Personality and Social Psychology, 84(4) $822-848$.

Brown, K., Ryan, R. \& Creswell, J. (2007). Mindfulness: Theoretical foundations and evidence for its salutary effects. Psychological Inquiry, 18(4), 211-237.

Bundick, M., Andrews, M., Jones, A., Mariano, J. M., Bronk, K. C. \& Damon, W. (2006). Revised youth purpose survey. Stanford, CA: Unpublished instrument, Stanford Centre on Adolescence.

Caldwell, K., Harrison, M., Adams, M. \& Quinn, R. (2010). Developing mindfulness in college students through movement-based course: Effects on self-regulatory selfefficacy, mood, stress, and sleep quality. Journal of American College Health, $58(5), 433-442$

Cardaciotto, L., Herbert, J., Forman, E., Moitra, E., \& Farrow, V. (2008). The assessment of present-moment awareness and acceptance: The Philadelphia Mindfulness Scale. Assessment, 15, 204-223. 
Carmody, J., Baer, R., Lykins, E. \& Olendzki, N. (2009). An empirical study of the mechanisms of mindfulness in a mindfulness-based stress reduction program. Journal of Clinical Psychology, 65(6), 613-626.

Carmody, J., \& Baer, R. (2009). How long does a mindfulness-based stress reduction program need to be? A review of class contact hours and effect sizes for psychological distress. Journal of Clinical Psychology, 65(6), 627-638.

Carver, C., Scheier, M. \& Weintraub, J. (1989). Assessing coping strategies: A theoretically based approach. Journal of Personality and Social Psychology, $56(2), 267-283$.

Carver, C. \& Scheier, M. (1998). On the self-regulation of behavior. New York: Cambridge University Press.

Cash, M. \& Whittingham, K. (2010). What facets of mindfulness contribute to psychological well-being and depressive, anxious, and stress-related symptomatology? Mindfulness, 1, 177-182.

Cavanagh, K., Strauss, C., Cicconi, F., Griffiths, N., Wyper, A. \& Jones, F. (2013). A randomised controlled trial of a brief online mindfulness based-intervention. Behaviour Research and Therapy, 51, 573-578.

Chambers, R., Lo, BYC, \& Allen, N. (2008). The impact of intensive mindfulness training on attentional control, cognitive style, and affect. Cognitive Therapy and Research, 32(3), 303-322.

Ciesla, J., Reilly, C., Dickson, K., Emanuel, A. \& Updegraff, J. (2012). Dispositional mindfulness moderates the effects of stress among adolescents: Rumination as a mediator, Journal of Clinical Child \& Adolescent Psychology, 41(6), 760-770. 
Cohen, S., Kamarck, T.\& Mermelstein, R. (1983). A global measure of perceived stress. Journal of Health and Social Behavior, 24, 385-396.

Crumbaugh, J. C. \& Maholick, L. T. (1967). An experimental study in existentialism: The psychometric approach to Frankl's concept of noogenic neurosis. In V. E. Frankl (Ed.), Psychotherapy and existentialism (pp. 183-197). New York: Washington Square Press.

Damon, W., Menon, J. \& Bronk, K. (2003). The development of purpose during adolescence. Applied Developmental Science, 7(3), 119-128.

Davis, M. \& Zautra, A. (2013). An online mindfulness intervention targeting socioemotional regulation in fibromyalgia: Results of a randomized controlled trial. Annals of Behavioral Medicine. Online publication.

DOI: $10.1007 / \mathrm{s} 12160-013-9513-7$.

Diehl, M., Hay, E. \& Berg, K. (2011). The ratio between positive and negative affect and flourishing mental health across adulthood. Aging and Mental Health, 15(7), 882-893.

Diener, E., Emmons, R. A., Larsen, R. J., \& Griffin, S. (1985). The Satisfaction With Life Scale. Journal of Personality Assessment, 49, 71-75.

Fahlman, S., Mercer, K., Gaskovski, P., Eastwood, A. \& Eastwood, J. (2009). Does a lack of life meaning cause boredom? Results from psychometric, longitudinal, and experimental analyses. Journal of Social and Clinical Psychology, 28(3), 307-340. 
Francis, L., Jewell, A. \& Robbins, M. (2010). The relationship between religious orientation, personality, and purpose in life among an older Methodist sample. Mental Health, Religion \& Culture, 13(7), 777-791.

Fredrickson, B. (2001). The role of positive emotions in positive psychology: The broaden-and-build theory of positive emotions. American Psychologist, 56(3), 218-226.

Fredrickson, B. \& Losada, M. (2005). Positive affect and the complex dynamics of human flourishing. American Psychologist, 60(7), 678-686.

French, S. \& Joseph, S. (1999). Religion and its association with happiness, purpose in life, and self-actualisation. Mental Health, Religion \& Culture, 2(2), 117-120.

Fronsdal, G. (2010). Mindfulness meditation homework. Retrieved from http://www.insightmeditationcenter.org/books-articles/articles/mindfulnessmeditation-homework/all/1/

George, L. \& Park, C. (2013). Are meaning and purpose distinct? An examination of the correlates and predictors. The Journal of Positive Psychology: Dedicated to furthering research and promoting good practice, 8(5), 365-375.

Giluk, T. (2009). Mindfulness, big five personality, and affect: A meta- analysis. Personality and Individual Differences 47, 805-811.

Glück, T. \& Maercker, A. (2011). A randomized controlled pilot study of a brief webbased mindfulness training. BioMedCentral Psychiatry, 11(175), 1-12.

Goleman, D. (1988) The Meditative Mind: The Varieties of Meditative Experience. G.P. New York: Putnam \& Sons. 
Greeson, J. M. (2009). Mindfulness research update: 2008. Complementary Health Practice Review, 14, 10-18.

Grossman, P., Niemann, L., Schmidt, S. \& Walash, H. (2004). Mindfulness-based stress reduction and health benefits: A meta-analysis. Journal of Psychosomatic Research, 57, 35-43.

Grossman, P. H. (2008). On measuring mindfulness in psychosomatic and psychological research. Journal of Psychosomatic Research, 64. 405- 408.

Haghight, R. (2007). The development of the Brief Social Desirability Scale (BSDS). Europe's Journal of Psychology, 3(4). Retrieved from http://ejop.psychopen.eu/article/view/417/315.

Hart, W. (1987). The art of living: Vipassana meditation as taught by SN Goenka. Singapore: Vipassana Publications.

Hayes, S., Strosahl, K. \& Wilson, K. (1999). Acceptance and commitment therapy: An experiential approach to behavior change. New York: The Guilford Press.

Hill, P., Burrow, A., Brandenberger, J., Lapsley, D. \& Quaranto, J. (2010). Collegiate purpose orientations and well-being in adulthood. Journal of Applied Developmental Psychology, 31, 173-179.

Hill, P., Burrow, A., O’Dell, A. \& Thornton, M. (2010). Classifying adolescents' conceptions of purpose in life, The Journal of Positive Psychology, 5(6), 466-473.

Hill, P., Burrow, A. \& Sumner, R. (2013). Addressing important questions in the field of adolescent purpose. Child Development Perspectives.

Hirst, I. S. (2003). Perspectives of mindfulness. Journal of Psychiatric and Mental Health Nursing, 10, 359-366. 
Hofmann, S. \& Sawyer, A. (2010). The effect of mindfulness-based therapy on anxiety and depression: A meta-analytic review. Journal of Consulting and Clinical Psychology, 78(2), 169-183.

Kabat-Zinn, J. (1990). Full Catastrophe Living: Using the Wisdom of your Mind to Face Stress, Pain and Illness. New York: Dell Publishing.

Kabat-Zinn, J. (1994). Wherever you go, there you are: Mindfulness meditation in everyday life. New York: Hyperion.

Kabat-Zinn, J. (2003). Mindfulness-Based interventions in context: Past, present, and Future. Clinical Psychology: Science and Practice, 10, 144-156.

Kang, C. \& Whittingham, K. (2010). Mindfulness: A dialogue between Buddhism and clinical psychology. Mindfulness, 1, 161-173.

Kashdan, T. \& Rottenberg, J. (2010). Psychological flexibility as a fundamental aspect of health. Clinical Psychology Review, 30, 467-480.

Kashdan, T. \& McKnight, P. (2013). Commitment to a purpose in life: An antidote to the suffering by individuals with Social Anxiety Disorder. Emotion. Online publication. DOI: 10.1037/a0033278.

Kavanagh, K., Strauss, C., Cicconi, F., Griffiths, N., Wyper, A. \& Jones, F. (2013). A randomized controlled trial of a brief online mindfulness-based intervention. Behaviour Research and Therapy, 51, 573-578.

Keyes, L. M., Shmotkin, D. \& Ryff, C. D. (2002). Optimizing well-being: The empirical encounter of two traditions. Journal of Personality and Social Psychology, 8(6), 1007-1022. 
Kiang, L. \& Fuligni, A.J. (2010). Meaning in life as a mediator of ethnic identity and adjustment among adolescents from Latin American, Asian, and European American backgrounds. Journal of Youth and Adolescence, 39, 1253-1264.

Kiang, L. (2012). Deriving daily purpose through daily events and role fulfillment among Asian American youth. Journal of Research on Adolescence, 22(1), 186-198.

King, L., Hicks, J., Krull, J., \& Del Gaiso, A. (2006). Positive affect and the experience of meaning in life. Journal of Personality and Social Psychology, 90(1), 170-196.

Krusche, A., Cyhlarova, E., King, S. \& Williams, M. (2012). Mindfulness online: a preliminary evaluation of the feasibility of a web-based mindfulness course and the impact on stress. BioMedicalJournal Open, 2, 1- 5.

Latzman, R. \& Masuda, A. (2013). Examining mindfulness and psychological inflexibility within the framework of Big Five personality. Personality and Individual Differences, 55, 129-134.

Lazarus, R. S. \& Folkman, S. (1984). Stress, appraisal, and coping. New York: Springer.

Leary, M., Adams, C. \& Tate, E. (2006). Hypo-egoic self-regulation: Exercising selfcontrol by diminishing the influence of the self. Journal of Personality, 74, 18031831.

Mackenzie, M., Carlson, L., Munoz, M. \& Speca, M. (2007). A qualitative study of Selfperceived effects of Mindfulness-Based Stress Reduction (MBSR) in a psychosocial oncology setting. Stress and Health, 23, 59-69. 
McKnight, P. \& Kashdan, T. (2009). Purpose in life as a system that creates and sustains health and well-being: An integrative, testable theory. Review of General Psychology, 13(3), 242-251.

Mike, A., Harris, K., Roberts, B. W. \& Jackson, J. J. (under review). Conscientiousness: lower-order structure, life-course consequences and development.

Morone, N., Lynch, C., Lossado, V., Liebe, K. \& Grecco, C. (2012). Mindfulness to reduce psychological stress. Mindfulness, 3, 22-29.

Muraven, M. \& Baumeister, R. (2000). Self-regulation and depletion of limited resources: does self-control resemble a muscle? Psychological Bulletin, 126(2), 247-259.

Muraven, M., Collins, R. L. \& Nienhaus, K. (2002). Self-control and alcohol restraint: An initial application of the self-control strength model. Psychology of Addictive Behaviors, 16, 113-120.

Nolen-Hoeksema, S. \& Morrow, J. (1991). A prospective study of depression and posttraumatic stress symptoms after a natural disaster: The 1989 loma prieta earthquake. Journal of Personality and Social Psychology, 61(1), 115-121.

Pennebaker, J. \& Seagal, J. (1999). Forming a story: The health benefits of narrative. Journal of Clinical Psychology, 55(10), 1243-1254.

Peterson, C., Park, N. \& Seligman, M. E. P. (2006). Greater strengths of character and recovery from illness. The Journal of Positive Psychology, 1(1), 17-26.

Pinquart, M. (2002). Creating and maintaining purpose in life in old age: A metaanalysis. Ageing International, 27(2), 90-114. 
Preacher, K., \& Hayes, A. (2004). SPSS and SAS procedures for estimating indirect effects in simple mediation models. Behavior Research Methods, Instruments, \& Computers, 36(4), 717-731.

Raudenbush, S. W., Bryk, A. S. \& Congdon, R. (2010). HLM 7: Hierarchical linear and nonlinear modeling. Lincolnwood, IL: Scientific Software International.

Reker, G. T. \& Peacock, E. J. (1981). The Life Attitude Profile (LAP): A multidimensional instrument for assessing attitudes toward life. Canadian Journal of Behavioral Science, 13, 264-273.

Reker, G., Peacock, E., \& Wong, P. (1987). Meaning and purpose in life and wellbeing: A life-span perspective. Journal of Gerontology, 42, 44-49.

Reker, G. \& Wong, P. (1988). Aging as an individual process: Toward a theory of personal meaning. In J.E. Birren \& V.L. Bengston (Eds.), Emerging theories of aging (pp. 214 - 256). New York, NY: Springer.

Robbins, M. \& Francis, L. J. (2010). The Teenage Religion and Values survey in England and Wales: An overview. British Journal of Religious Education, 32, 307-320.

Ryff, C. (1989a). Beyond Ponce de Leon and life satisfaction: New directions in quest of successful aging. International Journal of Behavioral Development, 12, 25-55.

Ryff, C. (1989b). Happiness is everything, or is it? Explorations on the meaning of psychological well-being. Journal of Personality and Social Psychology, 57(6) 1069-081.

Ryff, C. \& Keyes, C. (1995). The structure of psychological well-being revisited. Journal of Personality and Social Psychology, 69, 719-727. 
Ryff, C., Singer, B. \& Love, G. D. (2004). Positive health: connecting well-being with biology. Philosophical Transactions Royal Society London B, 1383-1394.

Scheier, M. F., Wrosch, C., Baum, A., Cohen, S., Martire, L. M., Matthews, K. A., Schulz, R. \& Zdaniuk, B. (2006). The Life Engagement Test: Assessing purpose in life. Journal of Behavioral Medicine 29(3), 291-298.

Schrovers, M. \& Brandsma, R. (2010). Is learning mindfulness associated with improved affect after mindfulness-based cognitive therapy? British Journal of Psychology, 101, 95-107.

Segal, Z. V., Williams, J. M. G. \& Teasdale, J. D. (2002). Mindfulness-based cognitive therapy for depression: A new approach for preventing relapse. New York: Guilford Press.

Seligman, M. (2002). Authentic Happiness: Using the New Positive Psychology to Realize Your Potential for Lasting Fulfillment. New York: Free Press/Simon and Schuster.

Semple, R., Lee, J., Rosa, D. \& Miller, L. (2010). A randomized trial of MindfulnessBased Cognitive Therapy for children: Promoting mindful attention to enhance social-emotional resiliency in children. Journal of Child and Family Studies, 19, 218-229.

Shapiro, S., Carlson, L., Astin, J. \& Freedman, B. (2006). Mechanisms of Mindfulness. Journal of Clinical Psychology 62(3), 373-386.

Sheldon, K. \& Houser-Marko, L. (2010). Self-concordance, goal-attainment, and the pursuit of happiness: Can there be an upward spiral? Journal of Personality and Social Psychology, 80, 325-339. 
Siegler, I. \& Brummet, B. (2000) Associations among NEO personality assessments and well-being at midlife: Faet-level analyses. Personality and Aging, 15(4), 710-714.

Shahar, B., Britton, W., Sbarra, D., Figueredo, A. \& Bootzin, R. (2010). Mechanisms of change in Mindfulness-Based Cognitive Therapy for depression: Preliminary evidence from a randomized controlled trial. International Journal of Cognitive Therapy, 3, 402-418.

Sheldon, K.M., Kasser, T., Smith, K. \& Share, T. (2002). Personal goals and psychological growth: testing an intervention to enhance goal attainment and personal integration. Journal of Personality, 70, 5-31.

Smith, B. \& Zautra, A. (2004). The role of purpose in life in recovery from knee surgery. International Journal of Behavioral Medicine, 11, 197-202.

Smith B., Dalen, J., Wiggins, K., Tooley, E., Christopher, .Bernard, J. (2008). The Brief Resilience Scale: assessing the ability to bounce back. International Journal of Behavioural Medicine, 15, 194-200.

Snyder, C. R., Sympson, S., Ybasco, F., Borders, T., Babyak, M., \& Higgins, R. (1991). Development and validation of the State Hope Scale. Journal of Personality and Social Psychology, 70(2), 321-335.

Stahl, B., Goldstein, E. \& Kabat-Zinn, J. (2010). A Mindfulness-Based Stress Reduction Workbook. Oakland, CA: New Harbinger Publications, Inc.

Steger, M., Frazier, P., Oishi, S. \& Kaler, M. (2006). The Meaning in Life Questionnaire: Assessing the presence of and search for meaning in life. Journal of Counseling Psychology, 53, 80-93. 
Steger, M., Kashdan, T. \& Oishi, S. (2008). Being good by doing good: Eudaimonic activity and daily well-being correlates, mediators, and temporal relations. Journal of Research in Personality, 42, 22-42

Thauberger, P., Ruznisky, S. \& Cleland, J. (1981). Avoidance of exeistential-ontological confrontation: A review of research. Psychological Reports, 49, 747-764.

Thompson, B. \& Waltz, J. (2007). Everyday mindfulness and mindfulness meditation: Overlapping constructs or not? Personality and Individual Differences, 43, 1875 1885.

Thompson, B. \& Waltz, J. (2010). Mindfulness and experiential avoidance as predictors of posttraumatic stress disorder avoidance symptom severity. Journal of Anxiety Disorders, 24(4), 409-415.

Treynor, W., Gonzalez, R. \& Nolen-Hoeksema, S. (2003). Rumination reconsidered: A psychometric analysis. Cognitive Therapy and Research, 27(3), 247-259.

Turiano, N., Pitzer, L., Armour, C., Karlamangla, A., Ryff, C. \& Mroczek, D. (2012). Personality trait level and change as predictors of health outcomes: findings from a national study of americans (MIDUS). The Journals of Gerontology, Series B: Psychological Sciences and Social Sciences.

Ulmer, A. Range, L. \& Smith, P. (1991). Purpose in life: A moderator of recovery from bereavement. Omega-The Journal of Death and Dying, 23, 279-289.

Wallace, A., \& Shapiro, S. (2006) Mental balance and well-being: Building bridges between Buddhism and Western psychology. American Psychologist, 61(7), 690701. 
Warren, R. (2002). The purpose driven life: What on earth am I here for? Grand Rapids, MI: Zondervan.

Watson, D., Clark, L. A. \& Tellegen, A. (1988). Development and validation of brief measures of positive and negative affect: The PANAS scales. Journal of Psychology, 54(6), 1063-1070.

Wegner, D. M., Broome, A. \& Blumberg, S. J. (1997). Ironic effects of trying to relax under stress. Behaviour Research and Therapy, 35, 11-21.

Weinstein, N., Brown, K. \& Ryan, R., (2009) A multi-method examination of the effects of mindfulness on stress attribution, coping and emotional well-being. Journal of Research in Personality, 43, 374-385.

White, K., Wagner, L., \& Furrow, J. (2010). Purpose in adolescence. What am I here for?: A qualitative examination on the expression, development and integration of purpose in at-risk and thriving male adolescents. International Journal of Existential Psychology and Psychotherapy, 3(1),1-16.

Zika, S., \& Chamberlain, K., (2011). On the relation between meaning in life and psychological well-being. British Journal of Psychology, 83(1), 133- 145. 


\section{Appendices}

\section{Pre-test measures (Appendix A - K)}

Demographics (Appendix A)

Mindfulness (Appendix B)

Youth Purpose Scale (exploration subscale) (Appendix C)

Life Engagement Test (Appendix D)

Purpose goals question (Appendix E)

Purpose Orientations Scale (Appendix F)

Mini-IPIP (Appendix G)

Satisfaction with Life Scale (Appendix H)

Perceived Stress (Appendix I)

Rumination (Appendix J)

Positive and Negative Affect Schedule (Appendix K)

\section{Daily Measures (Appendix L - P)}

Check if completed morning task (Appendix L)

Daily moods (Appendix M)

Perceived Stress (Appendix N)

Purpose (Appendix O)

Daily activities (Appendix P)

Treatment Protocol (Appendix Q - R)

Mindfulness Intervention (Appendix Q)

Control Group Protocol (Appendix R) 


\section{Appendix A}

\section{Demographics}

Age ___ (in years)

Gender (please select one): Male Female

Are you enrolled in school?

Part-time

Full-time

Distance Learning

What year in school are you?

1

2

3

4

Please indicate your ethnicity (i.e., the one you identify most with):

African-Canadian / Black

Hispanic / Latin American

Caucasian / White

First Nations/ Aboriginal

Asian / Asian Canadian

Middle Eastern

Other

Please circle the appropriate response below. On average, how well are you doing in school:

1. Generally receive A's in my classes

2. Generally receive B's in my classes

3. Generally receive C's in my classes

4. Generally receive D's in my classes

5. Generally do not receive passing grades in my classes

Please check the number that corresponds to the income of the household of your upbringing:

1- Lower Income

2- Lower Middle Income

3- Middle Income

4- Upper Middle Income

5- Upper Income

How many hours a week do you spend...

1. On the computer for social networking 
2. On the computer for reasons other than social networking

3. Engaging in rigorous, cardiovascular exercise

4. Doing yoga

5. Meditating

6. In extracurricular school-related activities

Appendix B

\section{Five Facet Mindfulness Questionnaire-Short form}

Please rate each of the following statements using the scale provided. Write the number that best describes your own opinion of what is generally true for you.

1- never or very rarely true; 2- rarely true; 3 - sometimes true; 4- often true; 5- very often or always true.

1. I'm good at finding words to describe my feelings.

2. I can easily put my beliefs, opinions, and expectations into words.

3. I watch my feelings without getting carried away by them.

4. I tell myself I shouldn't be feeling the way I'm feeling.

5. It's hard for me to find the words to describe what I'm thinking.

6. I pay attention to physical experiences, such as the wind in my hair or sun on my face.

7. I make judgments about whether my thoughts are good or bad.

8. I find it difficult to stay focused on what's happening in the present.

9. When I have distressing thoughts or images, I don't let myself be carried away by them

10. Generally, I pay attention to sounds, such as clocks ticking, birds chirping, or cars passing.

11. When I feel something in my body, it's hard for me to find the right words to describe it

12. It seems I am "running on automatic" without much awareness of what I'm doing.

13. When I have distressing thoughts or images, I feel calm soon after.

14. I tell myself that I shouldn't be thinking the way I'm thinking.

15. I notice the smells and aromas of things.

16. Even when I'm feeling terribly upset, I can find a way to put it into words.

17. I rush through activities without being really attentive to them.

18. When I have distressing thoughts or images I am able just to notice them without reacting.

19. I think some of my emotions are bad or inappropriate and I shouldn't feel them.

20. I notice visual elements in art or nature, such as colors, shapes, textures, or patterns of light and shadow.

21. When I have distressing thoughts or images, I just notice them and let them go.

22. I do jobs or tasks automatically without being aware of what I'm doing.

23. I find myself doing things without paying attention.

24. I disapprove of myself when I have irrational ideas. 


\section{Appendix C}

\section{Youth Purpose Scale (Bundick et al., 2006)}

Purpose exploration items

Please indicate how much you agree with each statement below.

1 - Strongly Disagree

7 - Strongly Agree

Seeking:

I am searching for meaning in my life.

I am looking for someone that makes my life feel meaningful.

I am always looking to find my life's purpose.

I am seeking a purpose or mission for my life.

I am always searching for something that makes my life feel significant. 


\section{Appendix D}

\section{The Life Engagement Test (LET) (Scheier, et al, 2006).}

Instructions and Items:

Please answer the following questions about yourself by indicating the extent of your agreement using the following scale:

$1=$ strongly disagree

$2=$ disagree

$3=$ neutral

$4=$ agree

$5=$ strongly agree

Be as honest as you can throughout, and try not to let your response on one question influence your response to other questions. There are no right or wrong answers.

1. There is not enough purpose in my life.

2. To me, the things I do are all worthwhile.

3. Most of what I do seems trivial and unimportant to me.

4. I value my activities a lot.

5. I don't care very much about the tings I do.

6. I have lots of reasons for living. 


\section{Appendix E}

\section{Purpose open-ended question.}

Describe your current goals for life. 


\section{Appendix F}

\section{Purpose Orientations Scale (Hill et al., 2010)}

Please rate the importance to you personally of each of these potential goals for life.

1 (Essential) 2 (Very Important) 3 (Somewhat Important) 4 (Not Important)

Participating in a community service program

Influencing social values

Helping others who are in difficulty

Helping to promote racial understanding

Developing a meaningful philosophy of life

Becoming involved in programs to clean up the environment

Being successful in a business of my own

Having administrative responsibility for the work of others

Being very well off financially

Creating artistic work (painting, sculpture, decorating, etc.)

Becoming accomplished in one of the performing arts (acting, dancing, etc.)

Writing original works (poems, novels, short stories, etc.)

Becoming an authority in my field

Obtaining recognition from my colleagues for contributions to my special field

Making a theoretical contribution to science

Influencing the political structure

Raising a family 


\section{Appendix G}

\section{Mini- IPIP (Donnelan, et al., 2006).}

Instructions: On the following pages, there are phrases describing people's behaviors. Please use the rating scale below to describe how accurately each statement describes you. Describe yourself as you generally are now, not as you wish to be in the future. Describe yourself as you honestly see yourself, in relation to other people you know of the same sex as you are, and roughly your same age. So that you can describe yourself in an honest manner, your responses will be kept in absolute confidence. Please read each statement carefully, and then fill in the bubble that corresponds to the number on the scale.

$1=$ Very Inaccurate $2=$ Moderately Inaccurate $3=$ Neither Inaccurate nor Accurate 4=Moderately Accurate 5=Very Accurate

1. Am the life of the party

2. Sympathize with others' feelings

3. Get chores done right away

4. Have frequent mood swings

5. Have a vivid imagination

6. Don't talk a lot

7. Am not interested in other people's problems

8. Often forget to put things back in their proper place

9. Am relaxed most of the time

10. Am not interested in abstract ideas

11. Talk to a lot of different people at parties

12. Feel others' emotions

13. Like order

14. Get upset easily

15. Have difficulty understanding abstract ideas

16. Keep in the background

17. Am not really interested in others

18. Make a mess of things

19. Seldom feel blue

20. Do not have a good imagination 


\section{Appendix H}

\section{Satisfaction With Life Scale (Diener et al., 1985)}

Using the 1-7 scale below, indicate your agreement with each item by choosing the appropriate number for each line. Please be open and honest in your responding.

1 - Strongly Disagree, 2 - Disagree, 3 - Slightly Disagree, 4 - Neither Agree nor Disagree, 5 - Slightly Agree, 6 - Agree, 7 - Strongly Agree

In most ways my life is close to my ideal.

The conditions of my life are excellent.

I am satisfied with my life.

So far I have gotten the important things I want in life.

If I could live my life over, I would change almost nothing 


\section{Appendix I}

\section{Perceived Stress Scale (Cohen, Kamarck \& Mermelstein, 1983)}

The questions in this scale ask you about your feelings and thoughts during the last week. In each case, you will be asked to indicate how often you felt or thought in a certain way.

$0=$ Never

$1=$ Almost Never

$2=$ Sometimes

3 = Fairly Often

$4=$ Very Often

In the last week, how often have you been upset because of something that happened unexpectedly?

In the last week, how often have you felt that you were unable to control the important things in your life?

In the last week, how often have you felt nervous and "stressed"?

In the last week, how often have you felt confident in your ability to handle your personal problems?

In the last week, how often have you felt that things were going your way?

In the last week, how often have you found that you could not cope with all the things that you had to do?

In the last week, how often have you been able to control irritations in your life?

In the last week, how often have you felt that you were on top of things?

In the last week, how often have you been angered because of things that were outside of your control?

In the last week, how often have you felt difficulties were piling up so high that you could not overcome them? 


\section{Appendix J}

\section{Rumination Scale (RRS; Treynor et al., 2003)}

People think and do many different things when they feel depressed. Please read each of the items below and indicate whether you almost never, sometimes, often, or almost always think or do each one when you feel down, sad, or depressed. Please indicate what you generally do, not what you think you should do.

1 almost never $\quad 2$ sometimes $\quad 3$ often $\quad 4$ almost always

1. Think about how alone you feel

2. Think "I won't be able to do my job if I don't snap out of this"

3. Think about your feelings of fatigue and achiness

4. Think about how hard it is to concentrate

5. Think "What am I doing to deserve this?"

6. Think about how passive and unmotivated you feel.

7. Analyze recent events to try to understand why you are depressed

8. Think about how you don't seem to feel anything anymore

9. Think "Why can't I get going?"

10. Think "Why do I always react this way?"

11. Go away by yourself and think about why you feel this way

12. Write down what you are thinking about and analyze it

13. Think about a recent situation, wishing it had gone better

14. Think "I won't be able to concentrate if I keep feeling this way."

15. Think "Why do I have problems other people don't have?"

16. Think "Why can't I handle things better?"

17. Think about how sad you feel.

18. Think about all your shortcomings, failings, faults, mistakes

19. Think about how you don't feel up to doing anything

20. Analyze your personality to try to understand why you are depressed

21. Go someplace alone to think about your feelings

22. Think about how angry you are with yourself 


\section{Appendix K}

\section{Positive Affect / Negative Affect Scale (Watson, Clark, \& Tellegen, 1988)}

This scale consists of a number of words that describe different feelings and emotions. Read each item and then mark the appropriate answer in the space next to that word. Indicate to what extent you generally feel this way, that is, how you feel on the average.

1 - Very Slightly or Not at All; 2 - A Little; 3 - Moderately; 4 - Quite a Bit; 5 Extremely

Tense

Sad

Hopeless

Irritable

Scared

Guilt

Ashamed

Joy

Attentive

Determined

At ease

Inspired

Enthusiastic

Interested

Distressed

Excited

Upset

Strong

Proud

Irritable

Jittery

Afraid 


\title{
Appendix L
}

\section{Daily activity check}

\begin{abstract}
AM
Please describe the activity you were assigned by this study to complete today:

PM

Please describe the activity you were assigned by this study to complete today:

Please rate the amount to which you engaged in this activity today:

1 (did not complete activity) 4 (engaged several times throughout the day)

1 I forgot the activity/ did not complete the activity

2 I remembered the activity but did not engage in it during the day

3 I remembered the activity and engaged in the activity at least once during the day.

4 I remembered the activity and I actively engaged in the activity several times throughout the day.
\end{abstract}




\section{Appendix M}

Positive Affect, Negative Affect and Anxiety (Watson, Clark, \& Tellegen, 1988)

This scale consists of a number of words that describe different feelings and emotions. Read each item and then mark the appropriate answer in the space next to that word. Indicate to what extent you felt this way TODAY, that is, how you feel today.

1 - Very Slightly or Not at All; 2 - A Little; 3 - Moderately; 4 - Quite a Bit; 5 Extremely

Nervous
Tense
Anxious
Sad
Hopeless
Irritable
Scared
Guilt
Worry
Ashamed

Relaxed
Calm
Joy
Attentive
Determined
Alert
At Ease
Inspired
Determined
Enthusiastic




\section{Appendix N \\ Daily Stress}

List the most stressful event of the day

How stressful or traumatic was this event 1 (not at all) to 7 (very stressful).

How much stress did you experience today 1 (not at all) to 7 (very much) 


\section{Appendix O}

\section{Daily Purpose}

Questions borrowed from Meaning in Life scale (Steger, Frazier, Oishi, \& Kaler, 2006)

Revised Youth Purpose Scale (Bundick et al., 2006),

Rate your agreement with the following statements

1 (absolutely untrue) to 7 (absolutely true)

My life has a clear sense of purpose

I have discovered a satisfying life purpose

My life has no clear purpose 


\section{Appendix P}

\section{Daily activities}

Did you engage in any of these activities today? Please check the box beside the question if you engaged in the activity in the last 24 hours.

If yes, how many minutes did you spend completing this activity today?

Pro-social activities

Did you volunteer your time?

Did you help someone (a friend, stranger) who was having a hard time?

Engaged in an activity to promote racial understanding

$\square$ Engaged in an activity to help the environment

Financial activities

$\square$ Did you do something today to benefit your financial future?

$\square$ Did you take part in any management activities?

$\square$ Spent time setting goals or objectives for the future of your potential business

$\square$ Spent time contemplating your spending and saving habits

Creative activities

$\square$ Did you engage in creative writing or poetry?

$\square$ Did you create artistic work (painting, sculpture, decorating, etc.)?

$\square$ Expressed yourself creatively through dance or singing

$\square$ Viewed or appreciated creative or artistic expression

Mindful activities

$\square$ Did you practice yoga?

$\square$ Did you meditate?

$\square$ Did you go for a walk without listening to music or talking, and take in the sights around you?

Listen carefully to someone talking?

Other activities

$\square$ Check social media such as Facebook, Twitter or Instagram

$\square$ Hang out with friends

$\square$ Watch TV

$\square$ Engage in physical activity (run, gym, sports, excluding yoga?) 


\section{Appendix Q}

\section{Mindfulness Intervention}

\section{BEFORE:}

Make sure you have a quiet place to sit where you will not be disturbed.

Have you ever starting eating a snack, taken a couple bites, then noticed all you had left was an empty package? Or have you been driving somewhere and arrived at your destination with no recollection about your journey? Most people have had these experiences of "mindlessless" or "auto-pilot" in their daily lives. Without being aware or "present" in our own lives, we may fail to notice the good things around us, fail to get signals from our bodies, or be wrapped up in negative self-talk.

Mindfulness is essentially being aware of what you are doing, while you are doing it, with an attitude of non-judgment and non-reactivity. This state of attention can be brought to any activity you are engaging in.

See if you can pay more careful attention to allow yourself to see what is happening in your own body and mind, and around you.

Take a deep breath. And notice the feeling of the ground under your feet and the feeling of your breath moving in and out of your body.

Notice and become aware of any self-evaluation or resistance as you complete the exercise. See if you can adopt an attitude of taking things as they are without reacting, and not judging or labeling your experience as good/bad.

\section{Daily Exercises:}

Day 1: Beginner's mind- observing the environment around you with curiosity

Day 2: Engaging in a chore with mindfulness

Day 3: Noticing how the body feels through the day

Day 4: Noticing thoughts

Day 5: Emotion regulation- noticing negative thoughts, not reacting. Run out an emotion. 
Day 1: Beginner's mind- observing and describing environment around you

\section{Experiential task- Day 1}

Look around you, as if you are seeing your room for the first time. Take a moment to observe your surroundings and notice the sensory details: what does the air smell like, how does the keyboard feel on your fingertips? Listen and look around you, make a note about what you hear or see and then move on.

Describe in as much detail as possible 1 object you SEE in the environment around you. Just note things that you can observe with your senses and not anything you previously know about the object. Write in as much detail about the object that you can.

Describe 3 things you HEAR in your environment external environment

Describe 3 things you HEAR in your internal environment (body)

\section{Exercise- Day 1}

There are many moments through out the day when you have to wait for something, whether you're standing in line or waiting for your computer to load. Instead of looking at your phone or thinking about things you have to do, try tuning into your surroundings and observe something as if for the first time. Since you can't change the situation, you might as well use it as an opportunity to have a full-sensory experience.

As you go through your day today, really take notice and observe the environment around. Just take note of things around you that you normally would not pay attention to. A useful cue to remember to do this is anytime throughout the day that you're waiting for something, check in, look around and engage in this exercise.

\section{Day 2: Acting with awareness}

\section{Experiential task- Day 2}

The intention of mindfulness can be used in daily activity, by simply bringing your full attention to the task at hand, and just letting thoughts and feelings come and go without getting distracted by them.

Any activity can be done in a way that is mindful and acknowledges both the sensations in your body, and the sounds in the environment.

Today, we will do an everyday task such as writing, with an intention of doing it mindfully. Mindful writing is the act of writing with intention, awareness and nonjudgment of yourself. Keep your attention in the present moment and not think about other activities or other things you could be doing. Pay attention to sensations in your body, as these sensations may be clues that suggest images or feelings associated with the themes in your writing. 
Take the next 5 minutes and write freely about the topic "what am I feeling or thinking right now?" Just write whatever comes up, and don't worry about spelling, punctuation or even proper sentences, just allow yourself to become fully immersed in the process of writing and just keep writing. If you notice yourself judging what you are writing, or if your mind wanders, just bring yourself back to the task at hand.

\section{$\overline{\text { Exercise- Day } 2}$}

Often when we do the same tasks over and over again (such as brushing our teeth or washing dishes) we "zone-out" or go on automatic pilot, with little or no awareness to the task at hand.

Your exercise today is to, choose one routine physical activity that you perform most days, and experiment with doing it mindfully. Rather than going through the motions to get the task done, notice what you are doing and what it feels like. Feel water on your hands as you do the dishes, notice the softness of the sheets as you make your bed and feel the soles of your feet on the ground. To engage in the task mindfully it means doing just one activity while you are doing the exercise- not listening to music at the same time, for example. It is also best to let go of any concern about the results or in finishing quickly. Remain in the present as best you can. When the mind wanders, simply come back to the activity. Activities you might choose include brushing your teeth, eating a meal, washing the dishes or some routine act such as driving.

\section{Day 3: Noticing how the body feels}

\section{Experiential task- Day 3}

As we go through the day, thinking, talking, listening and writing, it is easy spend the entire day, "in your head" without noticing or paying attention to how your body is feeling. Learning to become present of sensations and reactions in your body to situations, foods or even thoughts can be an important tool to gauge reactions to events and regulate emotions before they get out of hand.

Gather and focus your attention. Redirect your attention to physical sensations in your body. For example, focus on your abdomen expanding as breath comes in and as breath goes out. Notice things such as the temperature of the air as you breathe in versus when you breath out, does the air feel warmer or cooler as it you breathe in than when you breathe out? Noticing your breath acts as an opportunity to anchor your self in present moment.

Recall a time or an experience when you felt excited or passionate about something. What sensations do you feel when you think of something exciting to you, or something you are passionate about?

Recall a time or experience when you felt worried about something. What does it feel like in your body when you think of something that worries you? 
Scan your body from your head to your toes, take three deep breaths and feel your breath expanding to different parts of the body. Notice the sensations in your body, as you continue to breathe deeply. What sensations do you FEEL? Describe 3 sensations you are currently feeling in your body.

\section{Exercise- Day 3}

As you go through your day, really take notice of how both the external environment and your thoughts influence how you FEEL in your body. Just notice how your body feels after doing things such as eating, sitting at your desk, talking with a friend or going for a walk. Use a repetitive task such as every time you enter a doorway, or every time you check your phone as a cue to mindfully check in with your body, and note how you are feeling.

What is the cue you will use to mindfully check in?

\section{Day 4: Noticing your thoughts}

\section{Experiential task- Day 4}

For a lot of people, there is a constant stream of random, disconnected thoughts constantly going through our brains. It is just jumping from one observation, sensation or reflection to the next. It could go along the lines of " what should I make for dinner? I could cut up chicken and fry it and then maybe I'll add veggies like broccoli. I love broccoli. I should eat really eat more vegetables. Maybe I should do a juice cleanse. What is the name of that book again? Hmm, maybe I should look it up later. I should read more, but I don 't' have time. What time is it anyway ...."

Today, we are learning to bring awareness to observe or witness the stream of thoughts, without getting wrapped up into any of them. Bring your awareness to your inner experience and acknowledge it by asking "what thoughts are going through my mind" and acknowledge mental events as they pass.

Turn toward any unpleasant feelings and acknowledge them without trying to make them different. Scan your body and notice any sensations of tightness or bracing to acknowledge the situation. Notice how different thoughts elicit reactions in your body.

Take the next 5 minutes to write freely about what you are thinking and note any feelings or sensations associated with these thoughts. Ask yourself the question: "What am I thinking and feeling right now?" Just write whatever comes up, and don't worry about spelling, punctuation or even proper sentences, just allow yourself to become fully immersed in the process of writing and just keep writing. If you notice yourself judging what you are writing, or if your mind wanders, just bring yourself back to the task at hand. 


\section{Exercise- Day 4}

Today, notice the thoughts that arise thorough out your day. See if you can simply observe your thoughts without having to react or elaborate on them. Track the things you think about. Remind yourself throughout the day to notice what you are thinking by using a simple cue such as every time you walk through a doorway or each time you pick up your phone.

Take notice of the content of your thoughts. Are the thoughts primarily self-referential or about others? Are your thoughts critical or judgmental? How frequently are your thoughts about things you "should" and "ought" to do? Are your thoughts primarily about the future, the past or a fantasy? Are your thoughts more optimistic or pessimistic? Are they apprehensive or peaceful? Are your thoughts content or dissatisfied? This exercise is not about judging the thoughts you have, it is just about noticing and becoming aware of the constant stream of chatter or self talk that is usually in the background. Take note of how different thoughts influence any reactions in your body.

\section{Day 5: Non-Judgment and Non-reactivity.}

\section{Experiential task- Day 5}

Observing one's internal and external environment, acting with awareness and being able to describe one's feelings and moods are components of mindfulness. But mindfulness also includes having a specific attitude towards one's experiences, specifically in a way that is non-judgmental and non-reactive.

Non-judgment refers to a particular way of being that does not label sensations, thoughts, and emotions as good/bad. Close your eyes and imagine a time you adopted this attitude of non-judgment. Imagine looking and interacting with yourself with a focus on this quality.

Describe a time that you were non-judgmental of your own experiences, thoughts and emotions.

To be non-reactive means that when unpleasant, distressing or positive emotions come up, the you are able to take things as they are, without getting wrapped up in these emotions or thoughts. Close your eyes and imagine a time you adopted this attitude of non-reactivity.

Describe a time what you were non-reactive of your emotions and thoughts.

\section{Exercise- Day 5}

Whether we like it or not, everyone experiences unpleasant emotions. When we do, it's easy to get wrapped up $\mathrm{n}$ the story associated with our feelings and spiral deeper into the darkness. Try to cultivate this non-reactive and non-judgmental attitude today as thoughts, feelings, and emotions come up. Notice, and acknowledge the experience then let it go. Next time you're feeling grumpy, impatient, or restless, take a deep breath and 
ask yourself if the part of you that is observing the emotion is feeling the same way. This will help you take your feelings less seriously so you don't end up feeling worse.

If you feel a strong desire, aversion, fear or other emotion, try not to act on the feeling. Just bring attention to feeling and observe changes as you observe it. Notice various body sensations and tensions, feelings of intensity, any attitudes and beliefs you have occurring with the presence of the emotion. If the emotion goes away, notice what its absence feels like.

\section{After Homework (on new screen)}

Please describe the activity you were assigned by this study to complete today:

New screen $\rightarrow$ display what daily task is.

\section{End of day:}

Please describe the activity you were assigned by this study to complete today:

Homework for the day is displayed.

Please rate the amount to which you engaged in this activity today:

1 (did not complete activity) 4 (engaged several times throughout the day)

1 I forgot the activity/ did not complete the activity

2 I remembered the activity but did not engage in it during the day

3 I engaged in the activity at least once during the day.

4 I actively engaged in the activity several times throughout the day. 


\section{Appendix R}

\section{Control Condition}

Positive Mood Induction

Think about the positive (uplifting) events that you have experienced in the past.

Recall a time you had a positive experience:

Day 1: Went on vacation

Day 2: Celebrated someone's birthday

Day 3: Got a good grade on a test or an assignment

Day 4: Received positive feedback from a job well-done.

Day 5: Had an enjoyable holiday

Take a few minutes, and write about this experience. Describe the event in as much detail as you like but at least try to write 3 sentences. Discuss how uplifted it made you feel.

\section{Exercise}

Today, think about the following affirmation that you can say to your self throughout the day:

Day 1: Life is a joy filled with delightful surprises

Day 2: If your attitude is good, then things are good and my attitude is good

Day 3: I feel cheerful and lively

Day 4: I've certainly got energy and self-confidence to share

Day 5: For the rest of the day, I bet things will go really well

\section{End of day:}

What was the positive affirmation that you thought about today:

The positive affirmation for the day is displayed.

Please rate the amount to which you engaged in this activity today:

1 (did not complete activity) 4 (engaged several times throughout the day)

1 I forgot the activity/ did not complete the activity

2 I remembered the activity but did not engage in it during the day

3 I engaged in the activity at least once during the day.

4 I actively engaged in the activity several times throughout the day. 